\title{
CEPREMAP
}

CENTRE POUR LA RECHERCHE ECONOMIQUE ET SES APPLICATIONS

\section{The Roots of Low European Employment: Family Culture?1}

\author{
Yann Algan ${ }^{2}$ and Pierre Cahuc ${ }^{3}$
}

Octobre 2005

Docweb nº512

\footnotetext{
${ }^{1}$ We thank Tito Boeri, Alessandra Fogli, Christopher Pissarides, Claudia Sénik and participants at the NBER International Seminar on Macroeconomics in Budapest and at the PSE seminar for very helpful comments. This paper is forthcoming in the NBER Marcroeconomics Annual 2005

${ }^{2}$ Université Marne la Vallée, CEPREMAP, IZA,OEP. Email: yann.algan@ens.fr

${ }^{3}$ University of Paris 1, CREST-INSEE, IZA, CEPR. Email: cahuc@ensae.fr.
} 


\title{
The Roots of Low European Employment: Family Culture?
}

\begin{abstract}
First we provide a simple labor supply model in which heterogeneity in family preferences can account for cross-country variations in both the level and the dynamics of employment rates of demographic groups. Second, we provide evidence based on international individual surveys that family attitudes do differ across countries and are largely shaped by national features. We also document that cross-country differences in family culture cause crossnational differences in family attitudes. Studying the correlation between employment rates and family attitudes, we then show that the stronger preferences for family activities in European countries may explain both their lower female employment rate and the fall in the employment rates of young and older people.
\end{abstract}

Key words: Employment rate, Family economics, Cultural economics

JEL: J12, Z10, D19

\section{Les faibles taux d'emplois européens: des origines culturelles?}

\begin{abstract}
Résumé
Les pays de l'OCDE se caractérisent par une très forte hétérogénéité de leur taux d'emplois. Cependant ces différences se concentre sur des groupes démographiques particuliers: les femmes, les jeunes et les seniors. Nous suggérons que cette hétérogénéité peut s'expliquer par des spécificités culturelles du modèle familial. Nous montrons tout d'abord, à l'aide de données internationales sur les valeurs individuelles, le degré d'hétérogénéité des conceptions nationales sur le rôle des jeunes, des femmes et des seniors. Nous montrons en particulier que cette hétérogénéité des valeurs est largement causée par des spécificités culturelles et non par l'environnement économique immédiat. Enfin nous estimons sur données agrégées l'importance déterminante du modèle familial traditionnel des pays d'Europe continentale et méditerranéenne dans la faiblesse de leur taux d'emploi féminin et la chute du taux d'emploi des jeunes et des seniors.
\end{abstract}

Mots clefs: Taux d'emploi, Famille, Culture et économie

JEL: J12, Z10, D19 


\section{Introduction}

OECD countries faced highly contrasted employment patterns over the last three decades. But this cross-national heterogeneity is mainly concentrated on particular demographic groups. Actually, Figure 1 shows that the employment rate of prime-age men has been quite similar across countries since 1970. In contrast, the employment rates of younger people, prime-age women and older people display significant cross-country variations. Moreover, Figure 1 shows that OECD countries also differ in the evolution pattern of the employment rates of demographic groups. All OECD countries have undergone the same steady rise in female employment rates and a slight decrease in prime-age male employment rates. But while the employment rates of younger and older individuals have remained quite stable in Anglo-Saxon and Scandinavian countries, they both have dramatically fallen in Continental and Mediterranean countries.

To the best of our knowledge, there is still no framework that explains such stylized facts which lie at the heart of the cross-country differences in aggregate employment rates over the last decades. The aim of this paper is to fill this gap. We argue that the key to understanding these stylized facts lies in family attitudes and labor supply interactions between the different generations of family members.

To that end, we provide a simple labor supply model that accounts for relations within the nuclear family and the extended family. In this framework, stronger preferences for nuclear and extended family relations lower the labor supply of women, younger and older people. Moreover, we show that an exogenous shock to the household production of women - such as the observed fall in the price of household durable goods - may have differential impact on the labor supply of each family members that depends on the extent of family relations. Following Greenwood et al. (2005), we relate the rise in female participation observed in all OECD economies to an exogenous decline in the price of durable goods used in household production. Specifically, this drop in the price of household durable goods allows women to substitute waged work to home production. The decline in the price of household durable goods also increases home production. Then, assuming that family activities ${ }^{4}$ are complementary to home production, all the members of the family have incentives to spend more time in family activities. This latter effect is more important when individuals are strongly attached to family activities. Therefore, the higher the weight put on family relations, the higher is the decline in the labor supply of younger and older individuals when prime-age female labor supply rises.

The empirical relevance of the model is then tested on international micro and macro data.

\footnotetext{
${ }^{4}$ We distinguish home production from family activities made up of leisure time that family members spend together.
} 
We first document that people living in different OECD countries do significantly differ with respect to their family attitudes. To that end, we use international social surveys on family values and relations (the World Value Survey and the International Social Survey Program) which cover the main OECD countries over the last two decades. These surveys allow us to disentangle the role played by individual characteristics and country fixed effects on family attitudes. Second, we show that these specific national family attitudes are highly correlated with the employment rates of the different demographic groups by running estimations on aggregate OECD data over the last two decades. This correlation pattern is generally robust to the inclusion of traditional timevarying labor market institutions and other country fixed effects which could account for other cross-country differences in institutions. ${ }^{5}$ We also stress that accounting for family attitudes is promising for understanding the dynamics of employment rates. By gathering a new database on the prices of household durable goods for an extensive set of OECD countries over the last two decades and controlling for labor market institutions, we find that the drop in the price of household durable goods has had stringent differential impacts on demographic groups across countries. This fall has been significantly correlated with the rise in female employment rates in all countries, consistently with Greenwood et al. (2005) results. But this effect goes beyond the nuclear family and significantly reduces the labor supply of younger and older individuals in Mediterranean and Continental countries while there is no evidence of such an interaction in Nordic or Anglo-Saxon countries.

This finding suggests that labor supply interactions within the nuclear and the extended family are a key element for understanding the evolution pattern of employment rates. ${ }^{6}$ From this perspective, if low employment in Europe originates in specific family culture ${ }^{7}$ widely shared by a majority of the population, the European employment strategy ${ }^{8}$ which aims at increasing the employment rate of women, younger and older people, may be inadequate as it might try to marketize services (such as child care or Sunday family meal for instance) that people prefer to produce at home. Accordingly, it is important to know whether the correlation between family attitudes and employment outcome can be interpreted as a relation where family culture causes

\footnotetext{
${ }^{5}$ Our approach does not aim at dismissing the influence of institutions on employment. We rather stress the influence of family attitudes that has been much less analyzed by economists. We view our paper as a step towards a more complete analysis that accounts for interactions between institutions, family attitudes and employment.

${ }^{6}$ According to Rogerson (2003) and Freeman and Shettkat (2005), the deterioration of the European employment rates relatively to the US comes from the higher weight put on home production in European countries. Blanchard (2004) provides a similar argument based on higher preference for leisure in European countries. But these explanations leave unexplained why only youth and elderly employment rates have dramatically fallen while female employment rates have steadily increased in European Continental and Mediterranean countries.

${ }^{7}$ By family culture, we mean common preferences for family rules, roles, habits, activities, and/or common household skills for home production.

${ }^{8}$ The European employment strategy is presented at: http://europa.eu.int/index_en.htm.
} 
employment outcomes.

The last contribution of the paper is thus an attempt at uncovering the causal link at work in the correlation between country specific family attitudes and employment patterns. It may be argued that heterogeneity in national family attitudes only mirrors heterogeneity in national institutions. To that regard, traditional explanations putting the emphasis on labor market rigidities and competition between demographic groups on the labor market may explain both employment rates $^{9}$ and family attitudes. ${ }^{10}$ In other words, the causality could go only from institutions to employment rates and family attitudes. We thus go one step further by providing some empirical evidence that national family attitudes are shaped by cultural primitives. In particular, we show that people facing a priori the same economic environment by living in the same country - but who differ by the national origin of their ancestors - do have significantly different family attitudes, even after controlling for all their relevant socioeconomic individual characteristics. ${ }^{11}$ Moreover, their family attitudes are perfectly in lines with those currently expressed in their country of origin.

The paper is organized as follows. Section 2 displays some stylized facts about the employment rates of different demographic groups for 19 OECD countries over the period 1970-2003. The labor supply model used to explain the employment participation of both prime age men, prime age women, young and old people is presented in section 3. Empirical evidence on the relation between family attitudes and employment rates are analyzed in section 4 . Section 5 offers some concluding comments.

\footnotetext{
${ }^{9}$ Bertola et al. (2004) and Wasmer (2001) argue that labor market rigidities hinder the employment of outsider groups (younger, women, and older individuals) or lead to more stringent crowding out effects between demographic groups. Yet this line of inquiry leaves unexplained the dynamics of employment rates. Over the last three decades, female employment rate has risen more in Mediterranean countries whose institutions are the most detrimental to outsiders. Inversely, male employment rates have decreased everywhere whatever their level of protection. Moreover the crowding out effects raised by a demographic shock such as the rise in female labor supply could be relevant in the short-run but are unlikely to persist over more than thirty years.

${ }^{10}$ Some papers have shown that family ties are influenced by the economic environment. Becker et al. (2004) and Fogli (2002) analyze the influence of job insecurity on youth emancipation decisions. Ermisch (1999), MartinezGranados and Ruis-Castillo (2002), Gianelli and Monfardini (2003) and Diaz and Guillo (2004) stress the importance of the access to housing.

${ }^{11}$ This type of empirical strategy has been used by Reimers (1985), Blau (1992), Antecol (2000), Guinnane et al. (2002), Giuliano (2004) and Fernandez and Fogli (2005). Blau (1992) and Guinnane et al. (2002) examine whether the fertility of immigrants differs from that of the native born in the US. Reimers (1985) and Antecol (2000) study the effect of the country of origin on the labor force participation of immigrants. Using the same approach, Giuliano (2004) focuses on family leaving arrangements and Fernandez and Fogli (2005) analyze female labor participation and fertility. All these studies find some significant influence of the cultural background on behaviors and economic outcomes.
} 


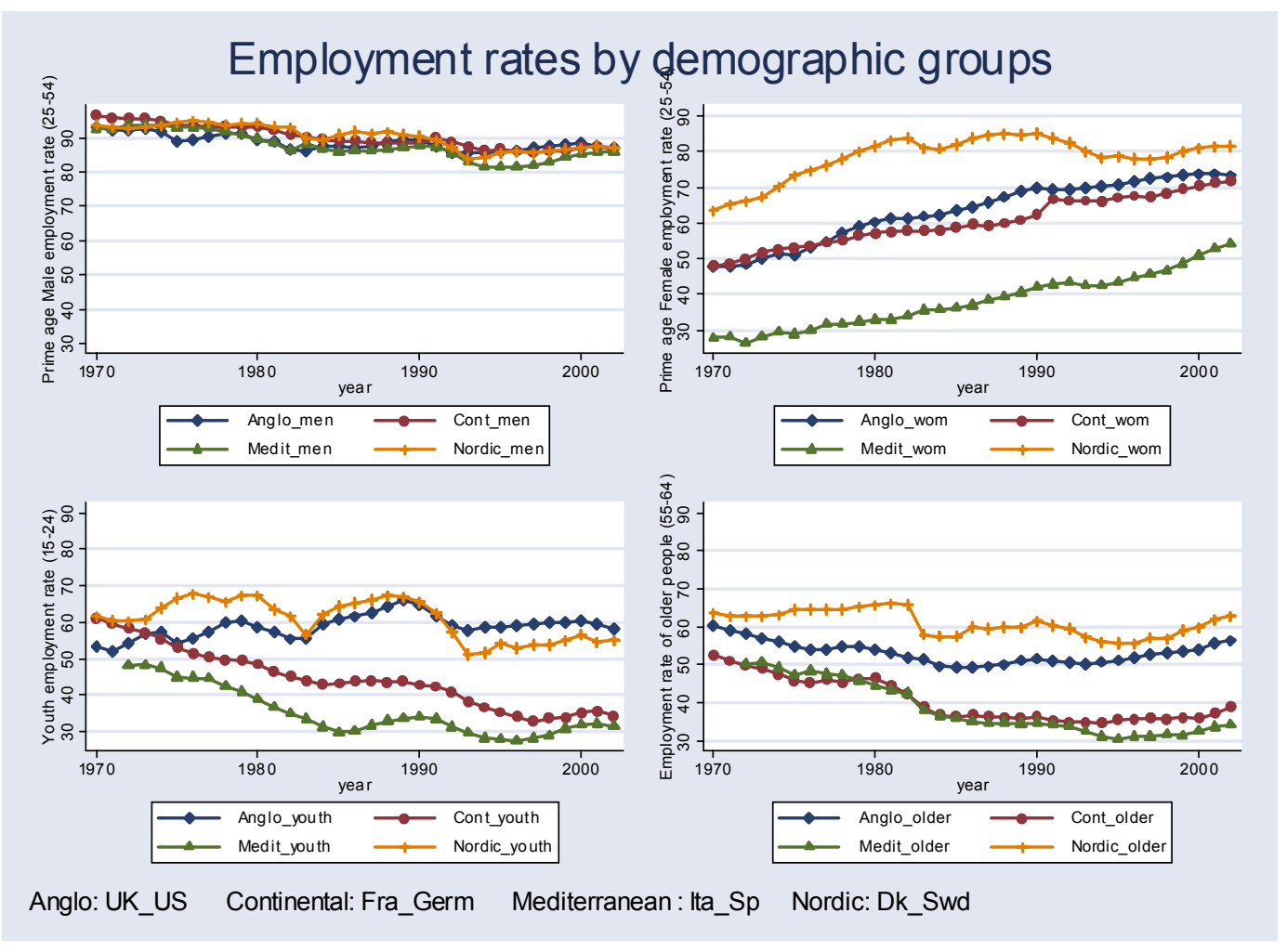

Figure 1: OECD employment rates by demographic groups over the period 1970-2003. Source: OECD 


\section{Stylized facts}

We begin by the main stylized facts concerning the employment rates of OECD countries over the last decades. The analysis covers the period 1970-2003 for 19 countries: Australia, Austria, Belgium, Canada, Denmark, Finland, France, Germany, Greece, Ireland, Italy, Japan, Netherlands, Norway, Portugal, Spain, Sweden, the UK and the US. In this realm, it is well known that Nordic and Anglo-Saxon countries are nowadays good performers whereas Continental European and Mediterranean countries are much less efficient. As of 2003, the employment rate of the 15-64 years old population reaches $73.2 \%$ in Nordic countries, $71.4 \%$ in Anglo-Saxon countries, but only $64.8 \%$ and $55.1 \%$ in Continental-European and Mediterranean countries respectively. ${ }^{12}$ Yet we show that the main cross-country and cross-temporal variations are concentrated on specific demographic groups.

\subsection{Dispersion of employment rates}

Table 1 indicates that the cross-national dispersion of prime-age male employment rates is much smaller than differences in the employment rates of other demographic groups, such as primeage women and younger and older people. Raw 2 in Table 1 indicates that the coefficient of variation (equals to the standard deviation over the mean) of prime age male employment rate over the whole period 1970-2003 is very small. It is about twenty times as small as the coefficient of variation at stakes for the other demographic groups, whose dispersion of employment rates is very close during this period.

Table 1: Employment rates in 19 OECD countries over the period 1970-2003. Source: OECD.

\begin{tabular}{lccccc}
\hline \hline Employment rate & $15-64$ & Male 25-54 & Female 25-54 & $15-24$ & $55-64$ \\
\hline (1) Mean 1970-2003 (\%) & 64.16 & 88.81 & 59.12 & 48.94 & 46.59 \\
(2) Coefficient of variation 1970-2003 (\%) & 1.57 & 0.33 & 6.87 & 6.44 & 6.86 \\
(3) Mean 1970 (\%) & 64.65 & 94.57 & 50.36 & 56.88 & 53.94 \\
(4) Coefficient of variation 1970 (\%) & 1.01 & 0.05 & 6.62 & 2.83 & 5.11 \\
(5) Mean 2003 (\%) & 67.38 & 86.76 & 70.36 & 44.88 & 49.43 \\
(6) Coefficient of variation 2003 (\%) & 0.83 & 0.06 & 1.34 & 8.35 & 5.93 \\
\hline
\end{tabular}

The third and fifth raws of Table 1 show that global employment rate increased by about 3 percentage points between 1970 and 2003. However, this global rise hides very different time-series employment patterns for the different demographic groups. On average, the relative

\footnotetext{
${ }^{12}$ The countries belonging to each cluster are: Anglo-Saxon (Australia, Canada, UK and US), European continental (Austria, Belgium, France, Germany, Netherlands), Mediterranean (Greece, Italy, Portugal, Spain) and Nordic (Finland, Norway, Denmark, Sweden).
} 
employment incidence of prime-age women rose steadily by 20 percentage points. Meanwhile, all the other demographic groups faced employment drops: 8 percentage points for prime-age men, 12 percentage points for younger people and 4 percentage points for older people.

It is also clear from raws 4 and 6 in Table 1 that the cross-country variation in prime-age male employment rates is much smaller than that of the other groups. In 2003, the coefficient of variation for the 25-54 years old men is more than 20 times as small as the coefficient of variation of prime-age women, 140 times as low as that of younger people and 98 times as low as the coefficient of variation for older people. Looking at the cross-temporal evolution in employment rates, it turns out that the coefficient of variation has decreased for women but has significantly increased for younger people (and to a lesser extent for older individuals) during the last decades. This evolution suggests a convergence in prime-age female employment rate concomitant to a divergence in the employment rates of younger and older individuals.

Accordingly, Table 1 makes plain that the whole differences in global employment rates across OECD countries stem from differences in the employment rates of specific demographic groups, namely prime-age women, and younger and older people. Moreover, the broad picture displayed by Table 1 suggests that the employment rates of these demographic groups evolved very differently: women participate more and more in the labor market while the other groups tend to be less and less employed.

\subsection{The universal rise in female employment rates}

Not only female employment rate did increase on average over the period 1970-2003 but it increased everywhere. Figure 2 displays the annual growth rate of female prime-age employment rate for each 19 OECD countries. It appears that this growth rate has been positive on average in each country, the rise being sharper in Ireland and Mediterranean countries. Yet cross-country comparison in level reveals that prime-age female employment rate remained much lower in Mediterranean countries than in Nordic and Continental European countries all over the period. Figure 3 illustrates this point for the year 2003. On average, 80 percent of prime-age women are employed in Nordic countries. This rate falls to approximately 70 percent in Continental European and Anglo-Saxon countries. And Mediterranean countries lag far behind with a primeage female employment rate no higher than 60 percent.

Thus when looking at female employment rate, two stylized facts emerge: i) a common rise in female employment rates in all countries over the last decades; ii) a persistent crosscountry heterogeneity in the level of employment rates. Most researches on female labor-market participation generally focus on the second stylized fact and put the blame on detrimental labor market or family policies. But this explanation is hardly compatible with the first stylized fact. 


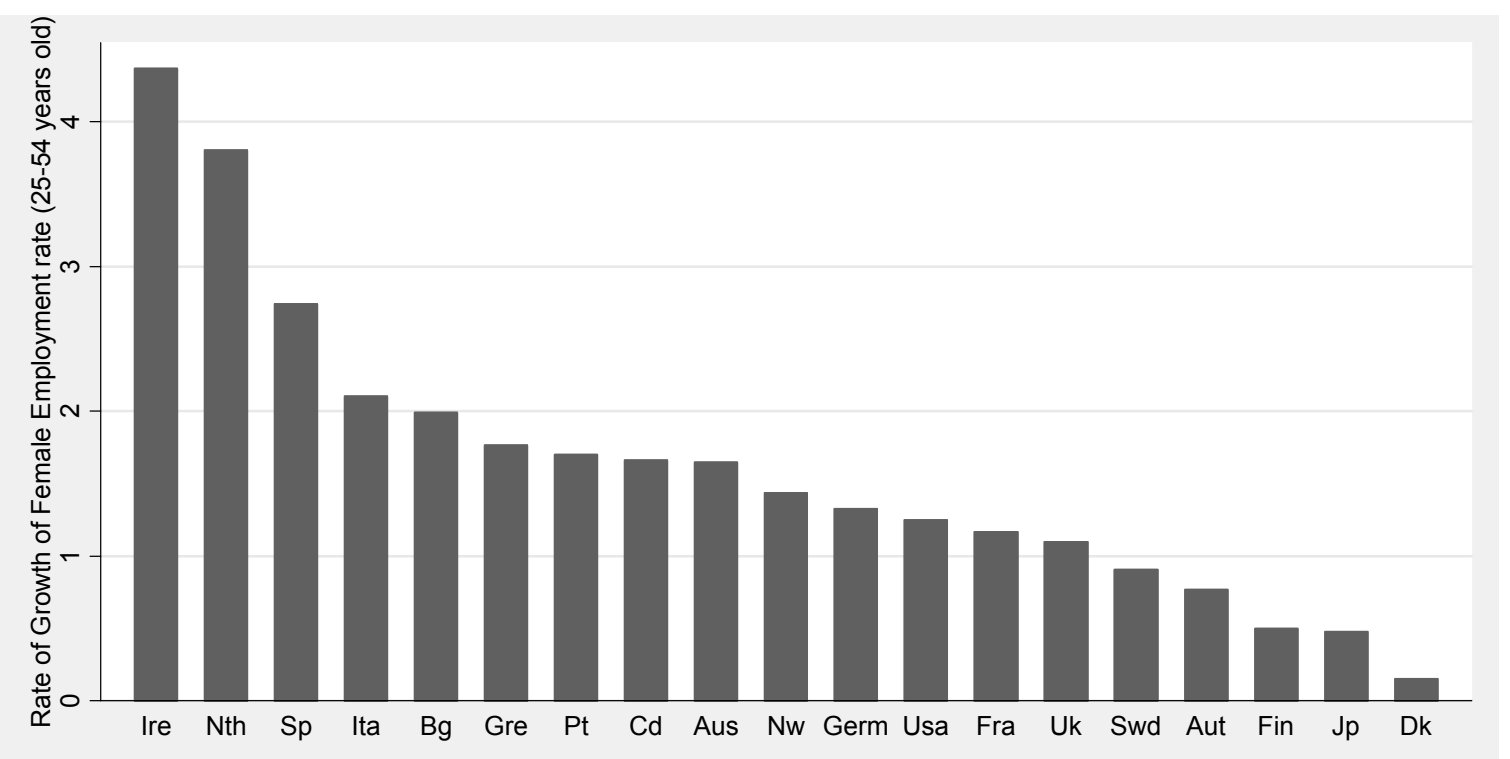

Figure 2: Annual rate of growth of prime age female employment rate in 19 OECD countries over the period 1970-2003.

The rise in female labor supply has been sharper precisely in Mediterranean and European Continental countries where institutions are usually said to be the most detrimental to female participation (Bertola et al., 2002).

\subsection{Diverse experiences for prime age men, younger and older people}

Whereas the female employment rate increased in all OECD countries, this is far from being the case for the other demographic groups.

Looking at prime-age men first, Figure ?? shows that their employment rates decreased almost everywhere. But a comparison of Figures 2 and ?? also reveals that cross-national differences in the growth rate of prime-age male employment rates are much smaller than that of women.

This picture contrasts with the labor market outcomes of younger individuals. Figure 5 shows that OECD countries faced very different changes in youth employment rates, the annual growth rate varying from -2 percent to 0.7 percent. This heterogeneity has had sizeable effects in the long-run. Let us compare France and the US as a textbook example to illustrate this point. The two countries started from approximately the same youth employment rate in 1970, around 52 percent. But while youth employment rate slightly increased over the period at an annual rate of .02 percent in the US, it dramatically fell at an annual rate of 1.4 percent in France. As a consequence , French youth employment rate lagged far behind its American counterpart with 


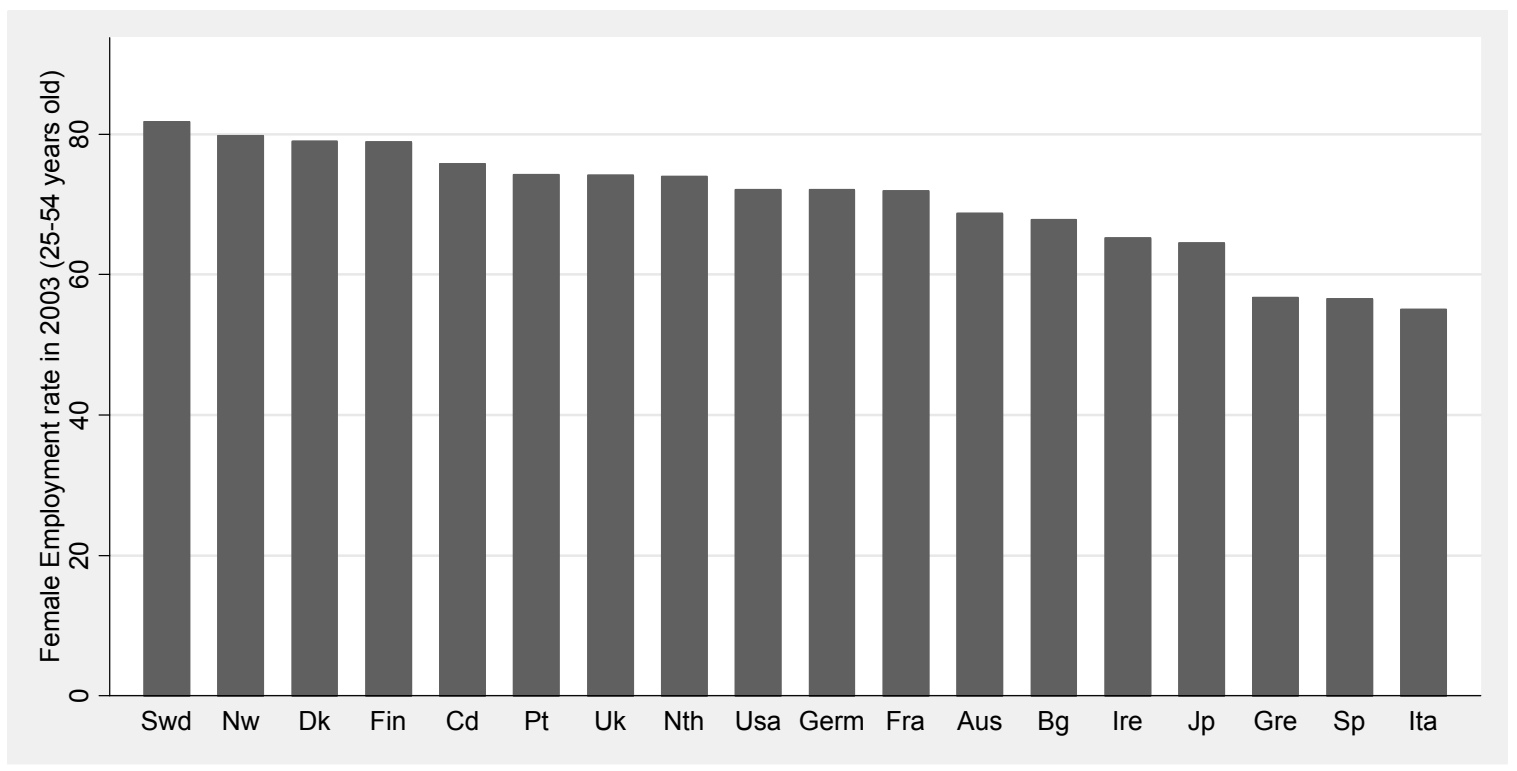

Figure 3: Prime age female employment rate in 2003. Source: OECD.

a level of 30 percent against 53 percent in the US in 2003. More generally, youth employment rate has decreased sharply in almost all European Continental and European countries while it has remained quite stable or has slightly increased in Anglo-Saxon and Nordic countries.

The employment patterns of older individuals offer a mirror image to that of the young generation. Figure 6 shows that OECD countries also faced very different changes in the employment incidence of older people. While their employment rates rose in almost all Anglo-Saxon and Nordic countries such as Denmark and the United Kingdom, they dramatically decreased in Continental European and Mediterranean countries such as France, Germany, Spain, Italy and Greece. Once again the comparison France - US is quite instructive. The employment gap for individuals aged between 55 and 64 years old has sharply widen from 5 percentage points to 25 percentage points over the period.

These stylized facts suggest that countries which have been able to keep high employment rates for younger people are also those that had good performances for older people. Figure 7 provides evidence on this strong positive cross country-correlation between the growth rate of the employment rates of young and older people. Countries like Denmark and Norway managed to increase employment for both the young and the old generations, whereas France, Germany and Spain had bad records for both populations.

As a preliminary conclusion, it appears that the evolution of OECD employment rates over the last thirty years is characterized by an universal increase in female employment rate and much 


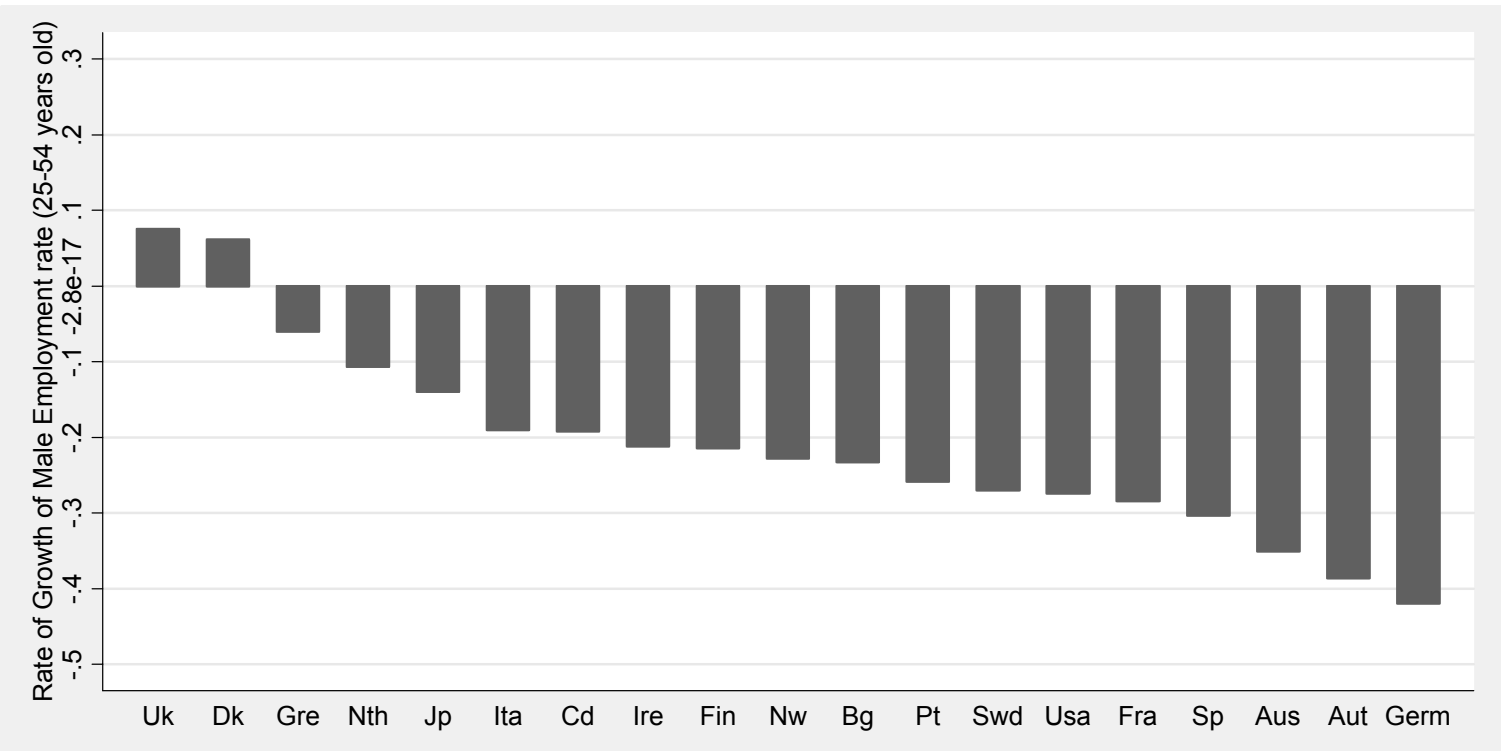

Figure 4: Annual rate of growth of prime age male employment rate in 19 OECD countries over the period 1970-2003.

more diverse experiences concerning the other demographic groups. As of 2003, countries with low aggregate employment rates have been unable to sufficiently raise the entry of women into the labor market to catch up the high female employment rate of Nordic countries. Moreover, countries which faced low female employment rates also suffered from the exit of younger and older people out of employment. Accordingly, the two questions that have to be addressed in order to explain the cross-country differences in employment rates over the last thirty years are:

i) Why is the prime-age female employment rate still low in some countries despite its rise common to all countries?

ii) Why did the employment rate of younger and older people decreased in some countries and not in others?

\section{The Model}

In this section, we provide a simple theoretical framework that allows us to explain the universal increase in the labor supply of prime-age women and the declining participation of other demographic groups in some countries over the last thirty years.

This framework highlights the differential impact of the observed decline in the relative price of household durable goods on the labor supply of the different demographic groups observed 


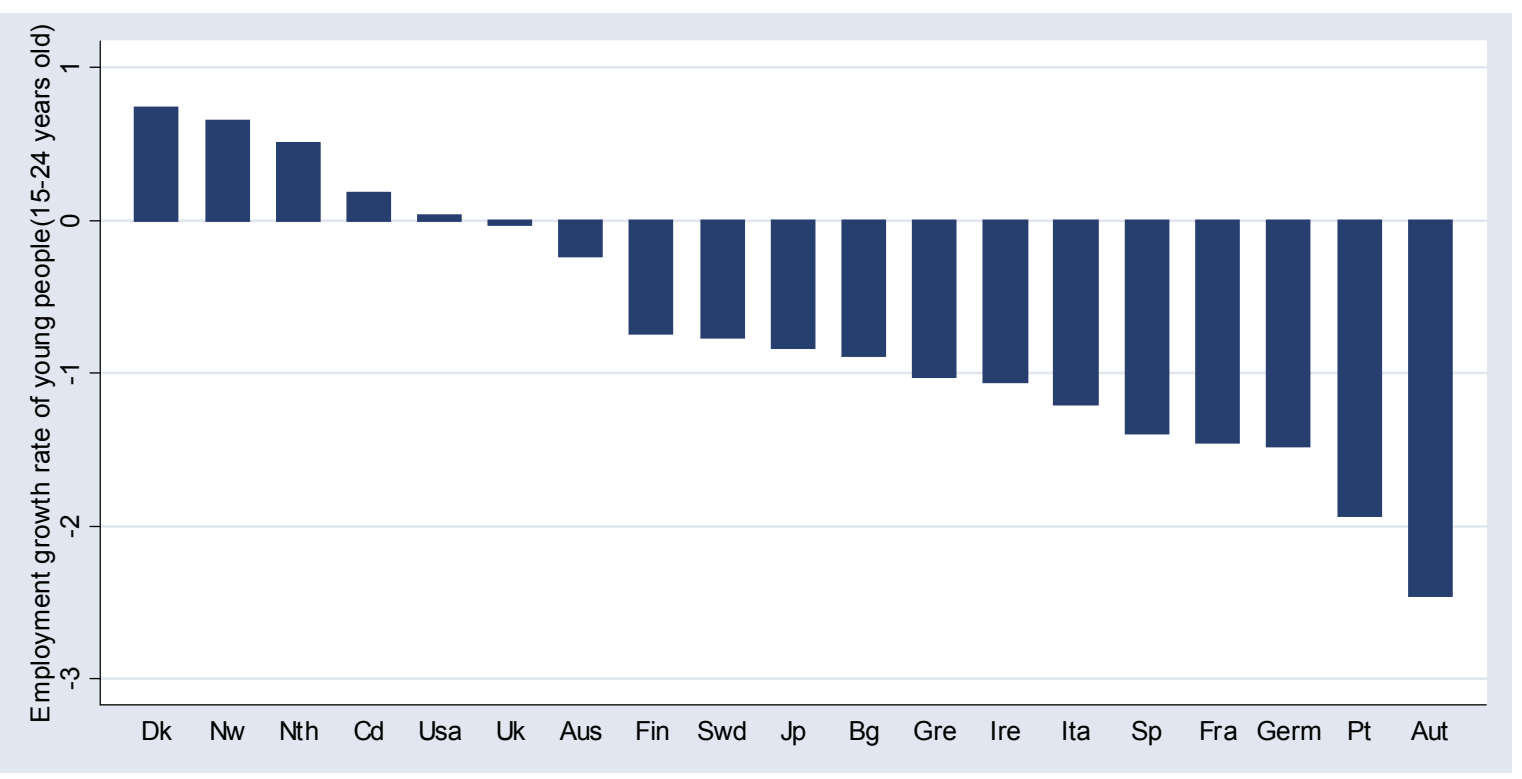

Figure 5: Annual growth rate of youth employment rate in 19 OECD countries over the period 1970-2003.

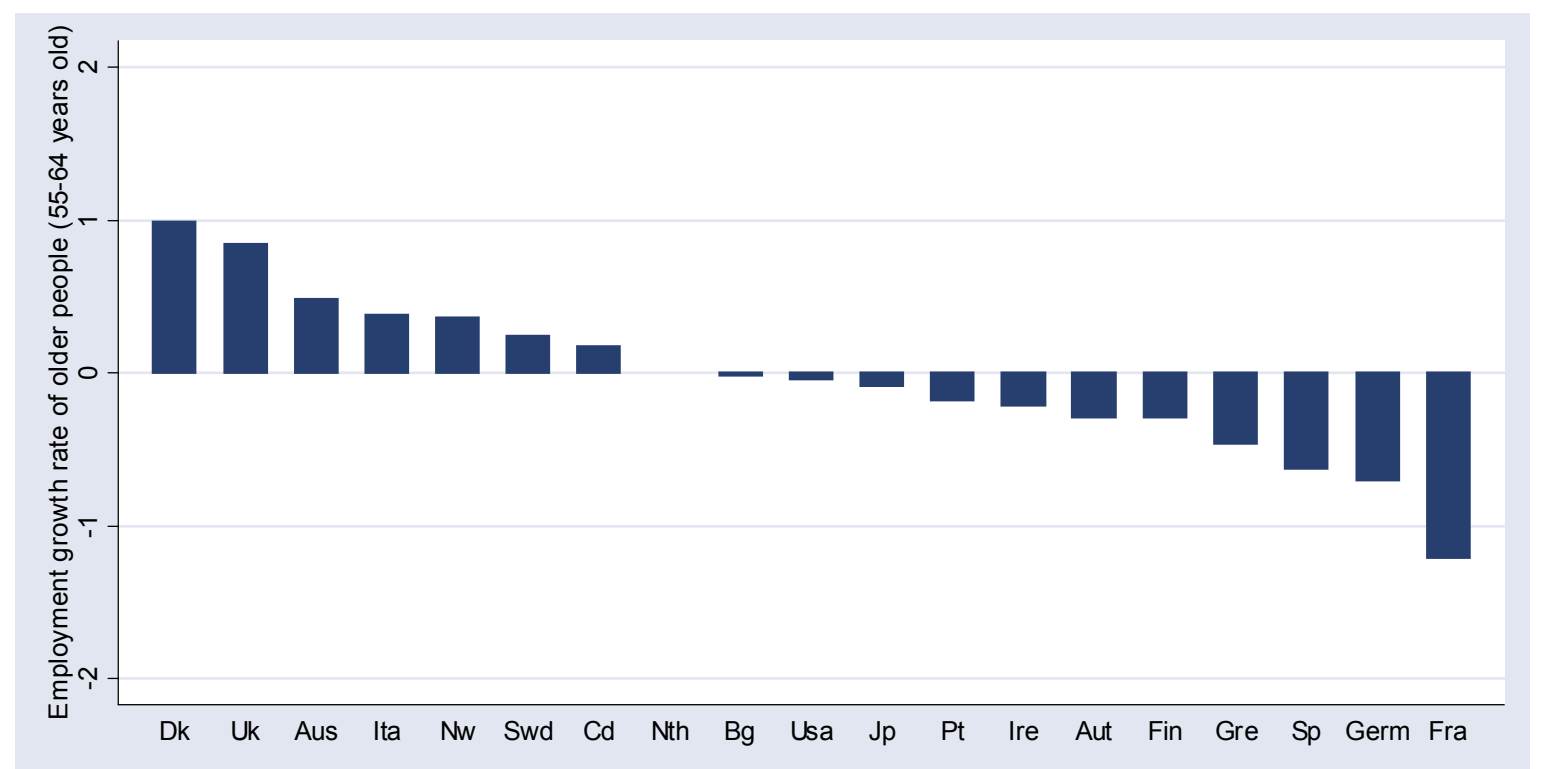

Figure 6: Annual growth rate of employment of older people in 19 OECD countries over the period 1970-2003. 


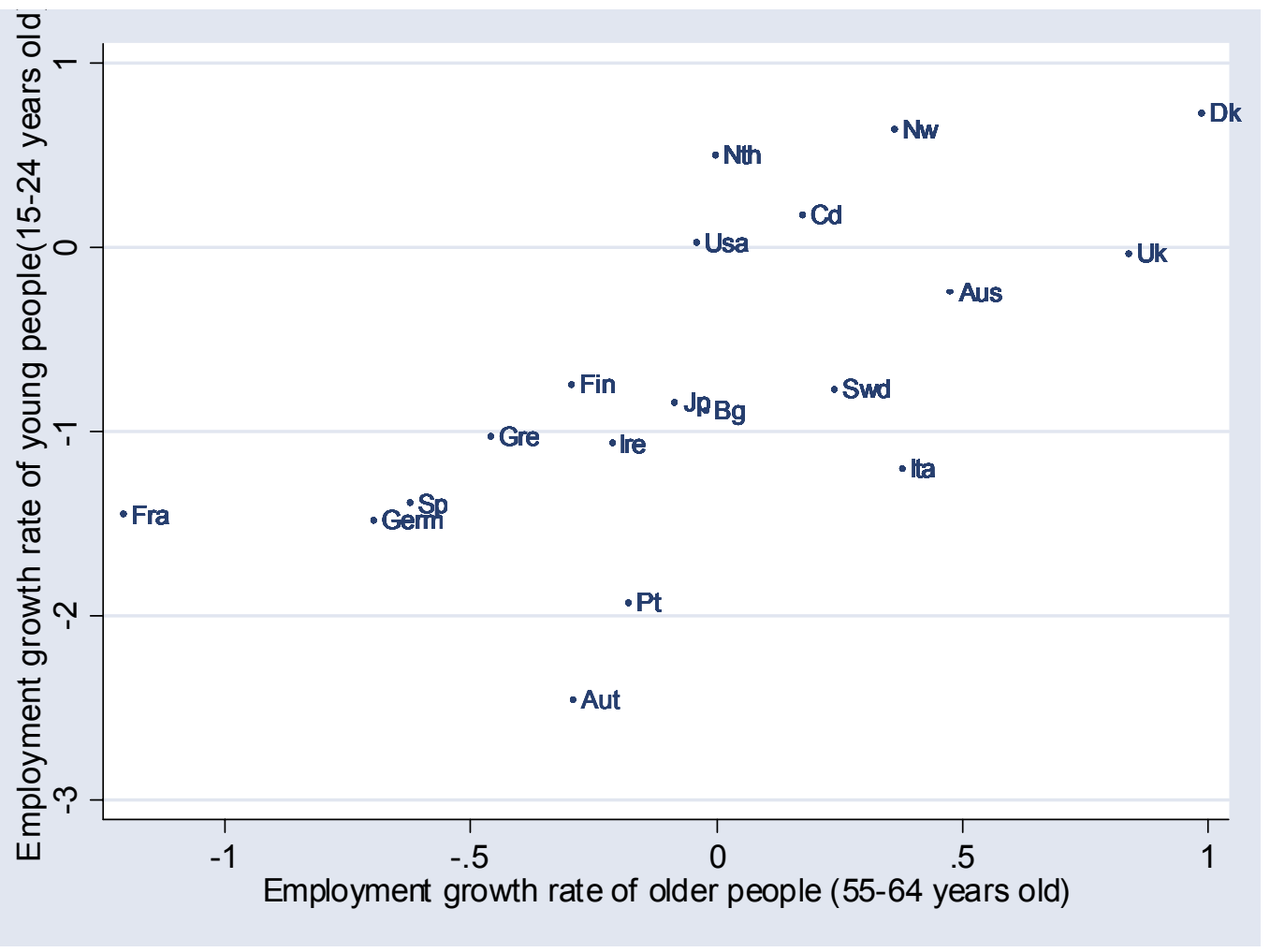

Figure 7: Correlation between the employment annual growth rates of young and older people. Source: OECD 1970-2003 
over the last decades. Such a decline has allowed women to substitute household durable goods to housework in the production of home goods. Accordingly, women have been able to enter into the labor market and to devote more time to leisure. Moreover, the drop in the household durable goods price influences the labor supply of other demographic groups through its impact on the production of home goods. Assuming that family activities and home production are complementary, increased home production triggered by the decline in the price of household durable goods creates incentives to devote more time to family activities, this effect being more important in economies in which individuals are strongly attached to family values.

This model allows us to incorporate in a simple framework the interactions between technology and family preferences. These two elements are generally considered as the main determinants of the increase in female labor market participation but are treated separately in the literature. Galor and Weil (1996) and Greenwood et al. (2005) argue that the rise in female labor force participation is due to technological shocks either on waged labor, with a change in the nature of jobs, or in the home sector, with the emergence of engines of liberation for female housework. But this technological explanation could not account by itself for cross-national differences in the level of female employment unless it assumes that such a technological shock has been restricted to specific OECD countries. Other explanations stress changes in social norms and family preferences as more and more women worked (Fernandez et al., 2004). This line of inquiry generally puts the emphasis on within country evolution of family preferences. We rather stress potential cross-country differences in family preferences at one point in time to document the differential impact of a common shocks on national employment rates.

The nuclear family

We consider the relations between spouses within the nuclear family in a simple standard model of the family (Bergstrom, 1997) in which we make the distinction between time devoted to home production, to family activities, to personal leisure and to waged work. The preferences of the nuclear family are represented by the utility function

$$
u\left(c, \ell_{m}, \ell_{f}, f\right)=\ln c+\lambda_{f} \ln \ell_{f}+\lambda_{m} \ln \ell_{m}+\phi \ln F
$$

where $c$ stands for consumption of a numeraire good purchased in the market; $\ell_{f}$ and $\ell_{m}$ denote female and male personal leisure respectively, $F$ represents a "family good". The parameters $\lambda_{i}$ $(i=f, m)$ and $\phi$ reflect the weight put on individual leisure and the family good respectively $\left(\lambda_{i}>0, \phi>0\right)$.

The family good is a composite of a good produced at home in quantity $c_{H}$, and leisure time 
that spouses spend together in family activities. Specifically

$$
F=\min \left(c_{H}, \mu_{f} s_{f}, \mu_{m} s_{m}\right),
$$

where $s_{f}$ and $s_{m}$ denote respectively the amount of time devoted by women and men to joint family activities. $\mu_{f}>0$ and $\mu_{m}>0$ are two parameters.

This formulation captures in a simple way the idea that there is a complementarity between home production and time that spouses devote together to family activities. Typically the time spent cooking at home is only valuable to the extent that the two spouses spend time to enjoy the resulting meal. Moreover this formulation allows us to extend the traditional literature by distinguishing personal leisure from family activities. This point might be key for understanding the EU-US employment gap. By ignoring this distinction, recent researches assume that the widening of the EU-US employment gap is only due to a shock in the preference for leisure (see Blanchard, 2004). Yet this shift towards non-work time could hide different non-market activities such as family activities. Naturally, this distinction is not neutral in terms of policy recommendations. ${ }^{13}$

Goods are produced in the home thanks to household durables $k$ and to female labor $h_{f}$. The production function reads

$$
c_{H}=\left[\eta h_{f}^{\frac{\sigma-1}{\sigma}}+(1-\eta) k^{\frac{\sigma-1}{\sigma}}\right]^{\frac{\sigma}{\sigma-1}}, \eta \in[0,1],
$$

where $\sigma>0$ is the elasticity of substitution between female time spent to housework and household durable goods.

Total time is normalized to unity for each individual. Female leisure equals total time, minus hours worked in the market, denoted by $m_{f}$, minus hours worked in the home, denoted by $h_{f}$, and minus hours spent with the spouse, denoted by $s_{f}$. That is

$$
\ell_{f}=1-m_{f}-h_{f}-s_{f} .
$$

Male leisure equals total time minus hours worked in the market and hours spent with the spouse

$$
\ell_{m}=1-m_{m}-s_{m}
$$

The budget constraint of the nuclear family reads

$$
c+p k+w_{m}\left(\ell_{m}+s_{m}\right)+w_{f}\left(\ell_{f}+h_{f}+s_{f}\right) \leq w_{f}+w_{m}+R \equiv W,
$$

\footnotetext{
${ }^{13}$ Freeman and Schettkat (2005) have stressed the empirical relevance of the distinction of non-market activities for understanding the EU-US employment gap. They distinguish four categories: market work, household work, leisure and personal time. They show that countries differ much more on household work rather than leisure.
} 
where $p$ is the price of the household durable good and $R$ stands for non labor income.

The maximization problem of the nuclear family reads

$$
\max _{\left\{c, k, h_{f}, s_{f}, s_{m}, \ell_{f}, \ell_{m}\right\}} \ln c+\lambda_{f} \ln \ell_{f}+\lambda_{m} \ln \ell_{m}+\phi \ln F,
$$

subject to (1), (2), (5) and $h_{f} \geq 0, s_{f}+h_{f}+\ell_{f} \leq 1, s_{m}+\ell_{m} \leq 1, k \geq 0 .{ }^{14}$

The first-order conditions for interior solutions can be written as

$$
\begin{gathered}
\ell_{i}=\frac{\lambda_{i}}{1+\lambda_{f}+\lambda_{m}+\phi} \frac{W}{w_{i}}, i=f, m, \\
h_{f}=\frac{W \phi\left(1+\lambda_{f}+\lambda_{m}+\phi\right)^{-1}}{p^{1-\sigma}\left(\frac{(1-\eta)}{\eta} w_{f}\right)^{\sigma}+w_{f}+\left(\frac{w_{f}}{\mu_{f}}+\frac{w_{m}}{\mu_{m}}\right)\left[\eta\left(\frac{w_{f}}{p}\right)^{\sigma-1}+(1-\eta)\right]^{\frac{\sigma}{\sigma-1}}}, \\
s_{i}=\frac{W \phi \mu_{i}^{-1}\left(1+\lambda_{f}+\lambda_{m}+\phi\right)^{-1}}{\left[(1-\eta)^{\sigma} p^{1-\sigma}+\eta^{\sigma} w_{f}^{1-\sigma}\right]^{\frac{\sigma}{\sigma-1}}+\left(\frac{w_{f}}{\mu_{f}}+\frac{w_{m}}{\mu_{m}}\right)}, i=f, m .
\end{gathered}
$$

According to these equations, our model yields the following main predictions. First, female housework $h_{f}$ increases with the price of the durable household good $p$ if the elasticity of substitution between female housework and durable household good is sufficiently high. More precisely, it turns out that female housework increases with $p$ if $\sigma>1$. Next, time devoted to family activity $s_{i}$ always decreases with the price of durable household goods. This result is due to the complementarity between home production and family activity. The higher the price of household durable goods $p$, the lower is the household production $c_{H}$, and the lower the time devoted by the two spouses devote to family activities.

As a consequence, the effect of household durable prices on the female time devoted to home production and family activity $\left(h_{f}+s_{f}\right)$ is a priori ambiguous. But it can be checked that there exists a threshold value of the elasticity of substitution, denoted by $\bar{\sigma}$, above which total time spend by women for family increases with $p$. Eventually, leisure, $\ell_{i}$, does not depend on the price of the durable household good in this simple setting.

Accordingly, this model shows that the drop in the price of durable household goods $p$ that occurred in the OECD countries may explain the rise in female labor supply and the decrease in male labor supply in a framework in which $i$ ) the elasticity of substitution between durable household goods and female homework is higher than $\bar{\sigma}$ and ii) family activity and the good produced in the home are complementary.

The model also predicts that more inclination for the "family good" (corresponding to higher values of $\phi$ ) decreases the labor supply of both women and men. However, the impact on the

\footnotetext{
${ }^{14}$ The utility function implies that the constraints $c \geq 0, \ell_{m} \geq 0, \ell_{f} \geq 0, s_{f} \geq 0, s_{m} \geq 0$ are never binding.
} 
labor supply of women is bigger because they devote more time to housework and to family activities whereas men spend more of their time in family activities only. Moreover, the absolute value of the derivative of female labor supply with respect to the price of household goods increases with $\phi$. This property may explain that women work less but that their labor supply is more responsive to changes in the prices of the durable household goods in countries in which individuals have stronger preferences for family activities.

\section{The extended family}

The members of the extended family are young adults and older people. They benefit from interactions with the nuclear family which allow them to consume a share $\varepsilon \in[0,1]$ of the good produced in the home of the nuclear family. ${ }^{15}$ We assume that nuclear family members derive the same utility from their own consumption as from the consumption of the extended family members up to the share $\varepsilon$. Thus this share enters into the utility of the nuclear family in the same way as the other part of the consumption. From this point of view, the parameter $\varepsilon$ can be interpreted as the intensity of the extended family ties.

Preferences of young adults and older people are represented by the utility function ${ }^{16}$

$$
v\left(c_{\varepsilon}, \ell_{\varepsilon}, f_{\varepsilon}\right)=\ln c_{\varepsilon}+\lambda_{\varepsilon} \ln \ell_{\varepsilon}+\phi_{\varepsilon} \ln F_{\varepsilon}
$$

where $c_{\varepsilon}$ denotes the consumption of the marketable good, $\ell_{\varepsilon}$ stands for leisure and $F_{\varepsilon}$ is the "family good". The parameters $\lambda_{\varepsilon}>0$ and $\phi_{\varepsilon}>0$ capture the weight put on individual leisure and the family good respectively. The definition of the family good is similar to that of the nuclear family. Specifically

$$
F_{\varepsilon}=\min \left(\varepsilon c_{H}, \mu_{\varepsilon} s_{\varepsilon}\right),
$$

where $c_{H}$ is the consumption of the good produced at the the nuclear family's home and $s_{\varepsilon}$ is the time devoted to family activities. To keep the model simple, we neglect potential home production by the members of the extended family.

The maximization problem of a member of the extended family reads

$$
\max _{\left\{c_{\varepsilon}, \ell_{\varepsilon}, s_{\varepsilon}\right\}} \ln c_{\varepsilon}+\lambda_{\varepsilon} \ln \ell_{\varepsilon}+\phi_{\varepsilon} \ln F_{\varepsilon}
$$

subject to the budget constraint

$$
c_{\varepsilon}+w_{\varepsilon}\left(\ell_{\varepsilon}+s_{\varepsilon}\right) \leq w_{\varepsilon}+R_{\varepsilon} \equiv W_{\varepsilon},
$$

\footnotetext{
${ }^{15}$ Introducing the possibility that members of the extended family also benefit from a share of the marketable good purchased by the nuclear family would keep unchanged the results obtained below.

${ }^{16}$ For the sake of simplicity, we do not distinguish potential differences in the valuation of leisure derived by the family members.
} 
and to the constraints (6) and $s_{\varepsilon}+\ell_{\varepsilon}+m_{\varepsilon} \leq 1 .{ }^{17}$ The parameters $w_{\varepsilon}$ and $R_{\varepsilon}$ denote the wage and the non labor income of the extended family members respectively.

The labor supply of the members of the extended family is given by the following first-order conditions

$$
m_{\varepsilon}=\left\{\begin{array}{c}
\max \left\{1-\frac{\left(\lambda_{\varepsilon}+\phi_{\varepsilon}\right)}{1+\lambda_{\varepsilon}+\phi_{\varepsilon}} \frac{W_{\varepsilon}}{w_{\varepsilon}}, 0\right\} \text { if } \frac{\mu_{\varepsilon} \phi_{\varepsilon}}{1+\lambda_{\varepsilon}+\phi_{\varepsilon}} \frac{W_{\varepsilon}}{w_{\varepsilon}} \leq \varepsilon c_{H}, \\
\max \left\{1-\frac{\lambda_{\varepsilon}}{1+\lambda_{\varepsilon}} \frac{W_{\varepsilon}}{w_{\varepsilon}}-\frac{\varepsilon c_{H}}{\left(1+\lambda_{\varepsilon}\right) \mu_{\varepsilon}}, 0\right\} \text { otherwise. }
\end{array}\right.
$$

It follows that the labor supply of young adults and older individuals decreases with the share $\varepsilon$ of the home production they can get. Moreover, a drop in the price of the durable household good also decreases their labor supply since home production increases and they can devote more time to family activities.

The predictions of the model can be illustrated by simple calibration exercises reported in Figures 8 and 9 . The values of the parameters are chosen as follows: $w_{f}=1, w_{m}=1.2$, $w_{\varepsilon}=1, \lambda_{m}=\lambda_{f}=0.1, \lambda_{\varepsilon}=1, R=R_{\varepsilon}=0, \mu_{m}=\mu_{f}=10, \mu_{\varepsilon}=2, \sigma=3, \eta=0.7, \phi_{\varepsilon}=$ $.3, \varepsilon=.5$. Wage values have been chosen to reproduce the average wage gap between men, on one hand, and women and members of the extended family, on the other hand, observed in OECD countries, which is about $20 \%$. The non labor incomes are assumed to be equal to zero for the sake of simplicity. The values of $\lambda_{i}, \mu_{i}$ and $\eta$ allow us to reproduce the average OECD participation rates of the different demographic groups and the share of household durable goods in total household expenditures in 2003 (which is about 8 percent in OECD countries according to Eurostat) for an intermediate value of $\phi=0.3$. Then, we choose a plausible value of the elasticity of substitution $\sigma$ that allows us to reproduce the typical changes in male and female labor market participation for a 50 percent drop in the price of the household durable good $p$ in countries with strong $(\phi=0.5)$ and weak $(\phi=0.1)$ preferences for the family good. Last, the values of $\phi_{\varepsilon}$ and $\varepsilon$ allow us to match the evolution of the market participation of younger and older people as members of the extended family.

Figure 8 displays the consequence of a decline in the price of the durable household goods on prime-age female and prime-age male labor supplies as a function of preferences for family activities. It entails a small decrease in prime-age male labor market participation (ranging between 86 percent and 84 percent) whatever the preference for family activities. However, the change in female labor supply is much more contrasted. The implied rise in prime-age female labor supply is much steeper when there is a strong preference for family activities $(\phi=0.5)$, going from 51 percent to 60 percent. In contrast, the increase in prime-age female labor supply is largely softened by weak family preferences $(\phi=0.1)$, ranging from 75 percent to 78.5 percent.

\footnotetext{
${ }^{17}$ The utility function implies that the constraints $c_{\varepsilon} \geq 0, \ell_{\varepsilon} \geq 0, s_{\varepsilon} \geq 0$ are never binding.
} 

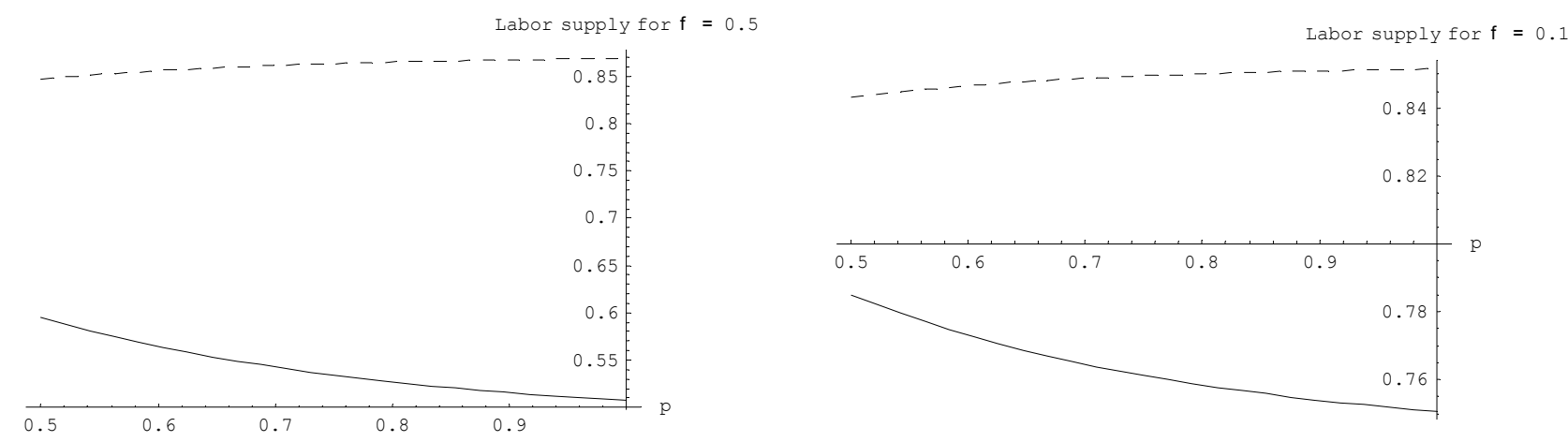

Figure 8: Female (continuous lines) and Male (dotted lines) labor supply with strong (left-hand side panel) and weak (right-hand side panel) preferences for the family good.

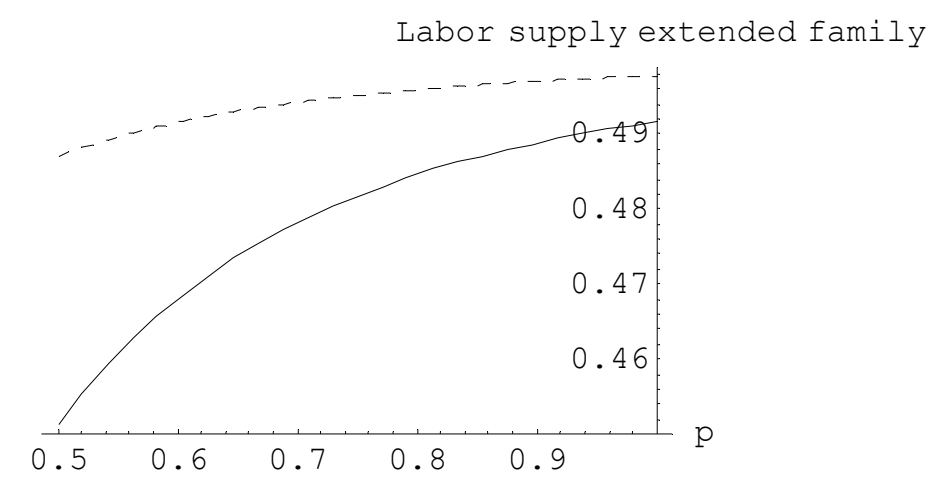

Figure 9: Labor supply of the members of the extended family with strong (continuous line) and weak (dotted line) preferences for the family good $(\phi=0.5$ and $\phi=0.1$ respectively).

Figure 9 looks at the effects of a similar decline in the price of the household durable goods on the labor supply of the extended family. While the labor supply of the extended family members remains quite stable in economies with low preferences for family, it dramatically falls in economies putting a high weight on family.

Figure 10 shows that our model can also account for similar changes in female employment rates concomitant with different changes in the employment rates of younger and older people. This can be seen by looking at the influence of family ties on the response of the labor supply of the extended family members to the decline in the price of durable household goods. When family ties are strong $\left(\varepsilon=0.9\right.$, the value of $\phi_{\varepsilon}$ being equal to 0.3 in both cases considered in Figure 10), the right-hand side panel of Figure 10 shows that the rise in female labor supply is compatible with is a 6 percentage points drop in the labor supply of the members of the 

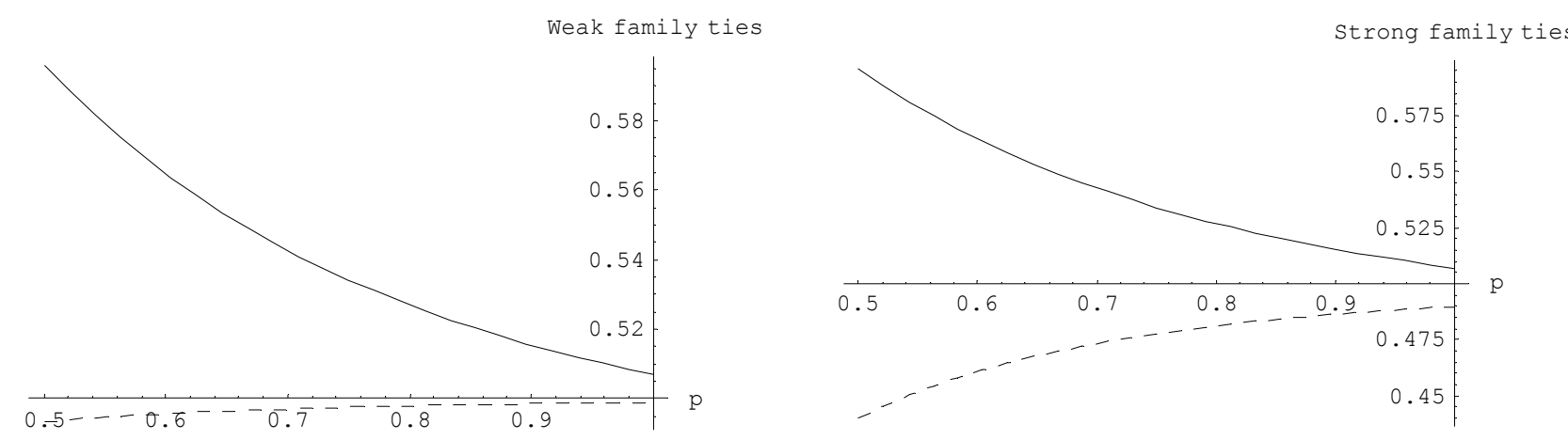

Figure 10: Female labor supply (continuous lines) and labor supply of the members of the extended family with strong family ties $(\varepsilon=0.9)$ and weak family ties $(\varepsilon=0.1)$.

extended family. By contrast, when family ties are weak $(\varepsilon=0.1)$, the same rise in female labor supply is concomitant to a 0.6 percentage point drop in the labor supply of the members of the extended family. From this point of view, our model allows us to explain why the US on one hand, and some Continental European countries such a Germany and France, on the other hand, had similar changes in female employment rate over the three last decades and very contrasted changes in employment rates of younger and older workers.

As a conclusion, this model predicts three main effects of a fall in durable good prices on the family labor supply: i) female labor supply increases, ii) male labor supply decreases and iii) the labor supply of young adult and senior decreases. Moreover, the size of the variations in labor supply depends on i) the preference $\phi$ for family and ii) the strength of family ties between the nuclear family and the members of the extended family measured by $\varepsilon$. If the nuclear family members put a higher weight on the family good ( $\phi$ large), a fall in the price of durable household goods entail a stronger increase in female labor supply and in household production. This rise in home production leads to a larger reduction in the labor supply of the extended family members, this effect being amplified by the importance of the extended family ties measured by the parameter $\varepsilon$.

The following part of the paper provides some empirical evidence which support these predictions. 


\section{Empirical evidence}

This section assesses the link between family attitudes and employment patterns of OECD countries over the last three decades. First, we stress that individuals living in different countries highly differ regarding attitudes towards prime-age people, and younger and older individuals, within the family and on the labor market. We also provide some elements indicating that crosscountry differences in family perceptions originate in cross-country differences in family culture. We then show that national family attitudes are highly correlated with the employment rates of the different demographic groups over the period, even after controlling for other potential country specific effects and time-period shocks. Eventually and consistently with the predictions of the labor supply model, we show that differences in national family attitudes are significantly correlated with the cross-national variation in the responses of the demographic employment rates following a common drop in the price of household durable goods.

\subsection{International heterogeneity in family culture}

This section documents to what extent people living in different OECD countries differ in their family perceptions. We then provide some evidence that these cross-national differences in family perceptions are deeply rooted in national family cultures.

First, we probe into attitudes towards the role of young individuals, old individuals and prime-age men and women within the family and on the labor market. ${ }^{18}$ To that end, we use international surveys on individual values: the World Value Survey (WVS) and the International Social Survey Programme (ISSP). The WVS covers four waves (1981-1984, 1990-93, 1995-1997, 1999-2002) and provides key questions on family attitudes. The ISSP complements these informations with specific surveys on gender roles and family relations since the mid-eighties. For the sake of comparison, our analysis will be restricted to the same 19 OECD countries: Australia, Austria, Belgium, Canada, Denmark, Finland, France, Germany, Greece, Ireland, Italy, Japan, Netherlands, Norway, Portugal, Spain, Sweden, UK and USA.

This first step allows us to show that there is a strong cross-country heterogeneity in family attitudes, even after controlling for observed individual heterogeneity. This finding raises the issue of the interpretation of such an heterogeneity. It can be the case that individuals express a traditional perception of family, according to which women should stay at home to raise children for instance, because they live in countries in which institutions are detrimental to female waged labor. In other words, does cross-country heterogeneity in family attitudes originate in cross-

\footnotetext{
${ }^{18}$ Recent studies have stressed cross-national variation in the allocation of time between market and home activities (Freeman and Schettkat, 2004). We complement this line of inquiry by laying stress directly on preferences and distinguishing the role played by each demographic groups in this realm.
} 
country heterogeneity in economic environments only? Or is this cross-country heterogeneity also ingrained in different national family culture, namely in heterogeneity in preferences for family ties and/or in household skills for home production? We shed some light on this issue by using direct information on the attitude of individuals living in the same country but whose ancestors came from different countries.

\subsubsection{Attitudes towards nuclear family}

We examine attitudes towards the nuclear family by looking at the perception of gender roles and parenthood.

\section{Gender roles}

We first consider the cross-national heterogeneity in the perception of gender roles on the labor market and within the family. Our primary interest lies in attitudes towards gender division of labor captured by the following questions: "When jobs are scarce, men should have more rights to a job than women" (WVS) and "Family life suffers if women wok full time" (ISSP). ${ }^{19}$ The first question is followed by the scale: "agree, neither, disagree". The answers to the other question are ranged between: "strongly agree, agree, disagree, strongly disagree".

To evaluate potential cross-national specificities in family attitudes, we make use of two indicators. The first one is based on average national preferences by reporting the mean reply to each question. Yet this naive indicator might capture heterogeneity in individual characteristics rather than national features. To overcome this flaw, we run ordered probit estimation for each question by controlling for the main individual characteristics and by including country-fixed effects which capture the role of specific national features. Regarding individual characteristics, we take into account the age and age squared, the level of education measured as the number of years in school, the marital status, the number of children, the family income coded by the surveys between low, middle and high incomes, and the employment status. Moreover, we control for the political affiliation coded by the surveys between left, center and right wings. We also include the religious affiliation by distinguishing the following main categories: Catholic, Protestant, Buddhist, Muslim, Jews, other religions and without any religion. All the estimations are based on the working age population between 16 and 64 years old.

Results are reported in Figure 11 for the available surveys in the nineties. The x-axis shows the mean reply at the country-level to each question. The basic picture is that of a great

\footnotetext{
${ }^{19}$ We checked that answers to other related questions yield similar results. These questions are: "If a woman earns more money than her husband, it is almost certain to cause problems" (WVS), "A university education is more important for a boy than a girl" (WVS), "Man's job is to earn money, wife's job is look after home and family" (ISSP).
} 
deal of heterogeneity across countries. On average Mediterranean countries, Japan, and to a lesser extent Continental European countries, put a much higher weight on gender division of labor within the family compared to Scandinavian and Anglo-Saxon countries. To give a hint of such variation, we re-scale the former question between 0-1 for (strongly) disagree and (strongly) agree. It turns out that in Japan, a majority of 57.1 percent of people do agree with job priority for men. The Mediterranean countries (Greece, Italy, Portugal and Spain) and the Continental European countries (Austria, Belgium, France, Germany, Netherlands) come next with 41.2 percent and 39.3 percent of agreement respectively. In the other Anglo-Saxon countries (Australia, Canada, United Kingdom, United States) and Nordic countries, this share of agreement sharply falls to 21.2 percent and 11.5 percent.

The y-axis reports the contribution of the specific country fixed effects to individual answers. The figure suggests that individual attitudes towards gender role is overwhelmingly shaped by national specificities. The correlation between the mean-reply and the country fixed effects is almost perfect, yielding a coefficient of determination equal to 0.9. Moreover, Table 2 reports that all country-fixed effects are statistically significant at the 1 percent level in explaining attitudes towards gender roles. Regarding individual characteristics, the male breadwinner conception is highly positively correlated with the number of children and the fact to be a man, to be married, to lean to the right wing and to belong to Catholic or Muslim denominations. In contrast, traditional gender role values are significantly negatively correlated with the level of education and to a lesser extent with the level of income.

\section{Parenthood}

A second important issue is whether differences in attitudes towards the nuclear family is driven by the representation of motherhood. This point is critical in as much as it could be linked to the observed cross-country heterogeneity in family policies and in gender employment gap (Jaumotte, 2003). We address this issue by using the two following questions: "A child needs both a mother and a father at home to grow up happily" (WVS), "A preschool child suffers if the mother works" (ISPP). The former question is available for the four waves of the WVS. The latter one is provided by ISPP for two specific waves on family attitudes in 1994 and 2002.

Figure 12 replicates the same exercise as before by plotting the mean response against the country-fixed effects concerning the two latter questions in the nineties and early 2000's. The picture is still that of a great cross-country heterogeneity mainly driven by national specificities, the correlation between the mean-reply and the fixed effects being close to one. To give a hint of such national variation, we group the answers into two categories: agree and disagree and use the same regional clusters as before. On average, the group of Mediterranean and 


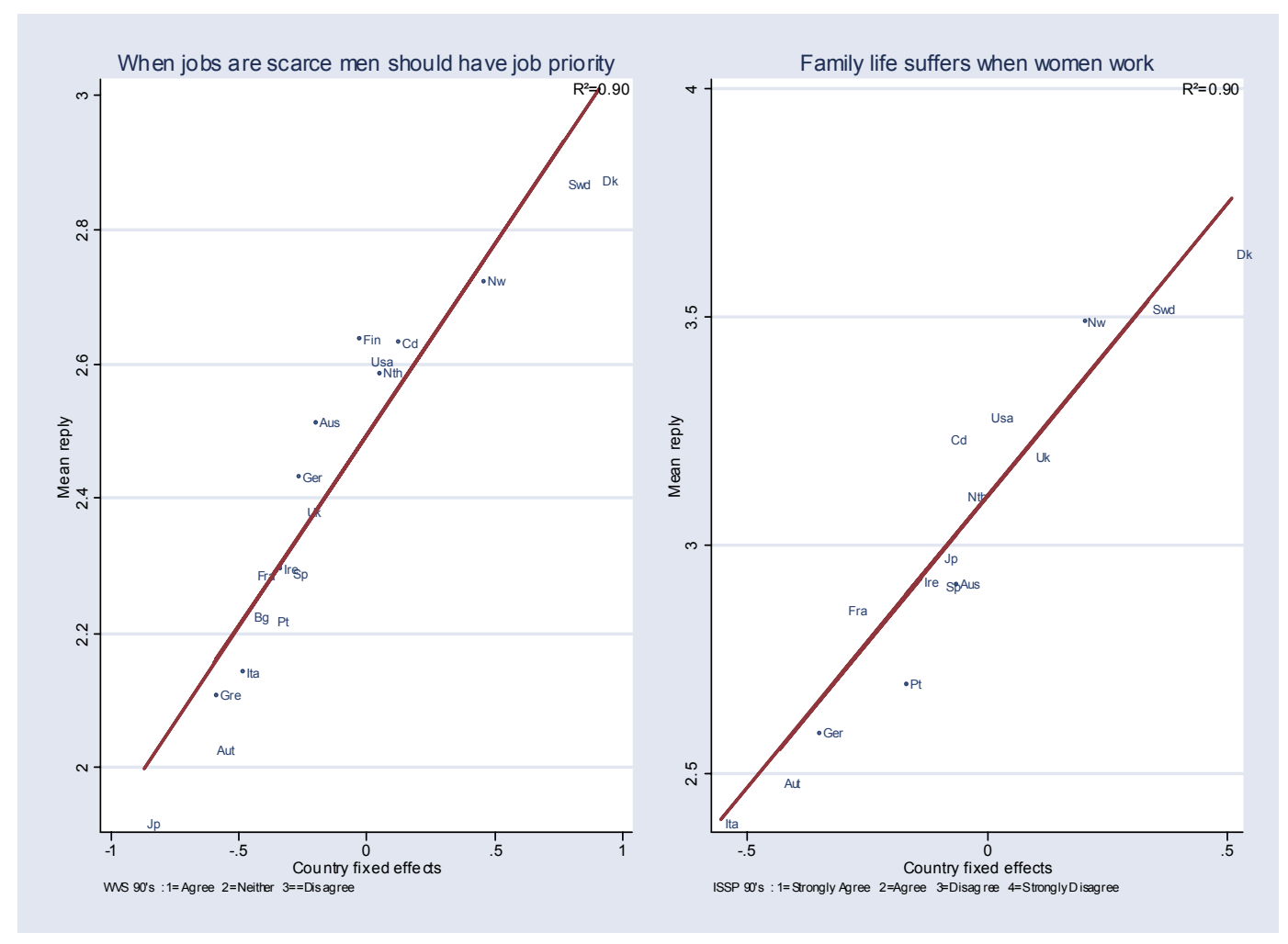

Figure 11: Conception of gender roles in OECD countries.

Continental countries do agree at 90 percent with the statement " $A$ child needs both a mother and a father at home to grow up happily". This share is reduced by 20 percent point when looking at Anglo-Saxon and Nordic countries. This difference becomes even sharper concerning the second statement "A preschool child suffers if the mother works". In typical Mediterranean and Continental European countries like Italy and Germany, 72 percent and 68 percent of people respectively share this traditional perception of motherhood. By contrast, they are no more than 38.3 percent in the United States and 30.4 percent in Sweden to back this statement. Obviously, such discrepancies may have strong links with female employment rates as documented in the next section.

\subsubsection{Attitudes towards extended family relations}

We extend our investigation on family attitudes to the role of young and elderly people within the extended family. A number of contributions (Fogli, 2000, Bentolila and Ichino, 2000) have stressed the cross-national variations in family arrangements between generations, in particular regarding the leaving age of children from parental household. In the following, we complement 


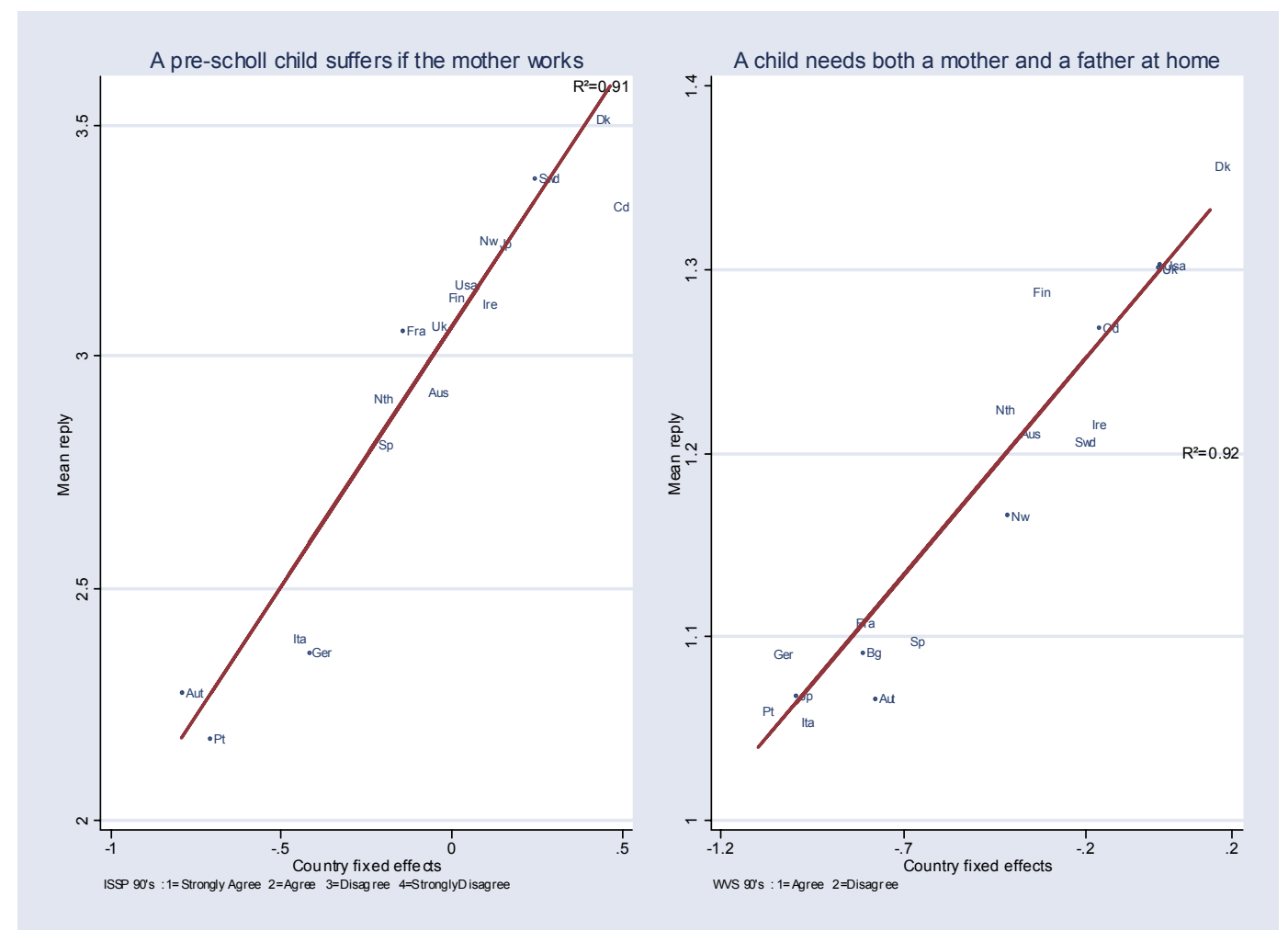

Figure 12: Conception of parenthood in OECD countries 
Table 2: Estimations of family attitudes: Ordered Probit Estimates

\begin{tabular}{|c|c|c|c|c|}
\hline & $\begin{array}{l}\text { Job priority } \\
\text { for men over } \\
\text { women (1) }\end{array}$ & $\begin{array}{l}\text { Preschool child } \\
\text { suffers if mother } \\
\text { works }(2)\end{array}$ & $\begin{array}{l}\text { Older people } \\
\text { should be forced } \\
\text { to retire early }(3)\end{array}$ & $\begin{array}{l}\text { Children shoulc } \\
\text { be taught to be } \\
\text { independent }\end{array}$ \\
\hline Male & $\begin{array}{l}-.222^{* *} \\
(.024)\end{array}$ & $\begin{array}{l}-.264^{* * *} \\
(.012)\end{array}$ & $\begin{array}{l}-.048^{* *} \\
(.023)\end{array}$ & $\begin{array}{l}-.135^{* * *} \\
(.019)\end{array}$ \\
\hline Age & $\begin{array}{l}-.018^{* *} \\
(.008)\end{array}$ & $\begin{array}{l}-.011^{* * *} \\
(.002)\end{array}$ & $\begin{array}{l}-.013 \\
(.008)\end{array}$ & $\begin{array}{l}.043^{* * *} \\
(.006)\end{array}$ \\
\hline Age2 & $\begin{array}{l}.000 \\
(.000)\end{array}$ & $\begin{array}{l}.000 \\
(.000)\end{array}$ & $\begin{array}{l}.000 \\
(.000)\end{array}$ & $\begin{array}{l}-.000^{* * *} \\
(.000)\end{array}$ \\
\hline Education & $.029^{* * *}$ & $.028^{* * *}$ & $.026^{* * *}$ & $.025^{* * *}$ \\
\hline (in years) & $(.003)$ & $(.001)$ & $(.002)$ & $(.002)$ \\
\hline Number & $-.046^{* * *}$ & $-.019^{* * *}$ & .001 & $-.042^{* * *}$ \\
\hline of child & $(.010)$ & $(.005)$ & $(.010)$ & $(.008)$ \\
\hline Partner & $\begin{array}{l}-.184^{* * *} \\
(.040)\end{array}$ & $\begin{array}{l}-.023 \\
(.015)\end{array}$ & $\begin{array}{l}-.074^{* *} \\
(.035)\end{array}$ & $\begin{array}{l}-.074^{* *} \\
(.029)\end{array}$ \\
\hline Employed & $\begin{array}{l}.163^{* * *} \\
(.020)\end{array}$ & $\begin{array}{l}.199^{* * *} \\
(.015)\end{array}$ & $\begin{array}{l}.025 \\
(.025)\end{array}$ & $\begin{array}{l}.085^{* * *} \\
(.021)\end{array}$ \\
\hline $\begin{array}{l}\text { Income class: } \\
\text { Middle }\end{array}$ & & & rence & \\
\hline Lower income & $\begin{array}{l}-.124^{* * *} \\
(.030)\end{array}$ & $\begin{array}{l}.029 \\
(.016)\end{array}$ & $\begin{array}{l}-.079^{* * *} \\
(.029)\end{array}$ & $\begin{array}{l}.016 \\
(.025)\end{array}$ \\
\hline Upper income & $\begin{array}{l}.126^{* * *} \\
(.030)\end{array}$ & $\begin{array}{l}.141^{* * *} \\
(.017)\end{array}$ & $\begin{array}{l}.047 \\
(.029)\end{array}$ & $\begin{array}{l}.032 \\
(.029)\end{array}$ \\
\hline $\begin{array}{c}\text { Political orientation: } \\
\text { Center }\end{array}$ & & & rence & \\
\hline Left & $\begin{array}{l}.108^{* * *} \\
(.029)\end{array}$ & $\begin{array}{l}.161^{* * *} \\
(.015)\end{array}$ & $\begin{array}{l}-.024 \\
(.027)\end{array}$ & $\begin{array}{l}.159^{* * *} \\
(.023)\end{array}$ \\
\hline Right & $\begin{array}{l}-.168^{* * *} \\
(.027)\end{array}$ & $\begin{array}{l}-.066^{* *} \\
(.016)\end{array}$ & $\begin{array}{l}-.005 \\
(.026)\end{array}$ & $\begin{array}{l}-.089^{* * *} \\
(.022)\end{array}$ \\
\hline $\begin{array}{l}\text { Religious affiliation: } \\
\text { No_religion }\end{array}$ & & & rence & \\
\hline Catholic & $\begin{array}{l}-.166^{* * *} \\
(.036)\end{array}$ & $\begin{array}{l}-.088^{* * *} \\
(.021)\end{array}$ & $\begin{array}{l}-.144^{* * *} \\
(.035)\end{array}$ & $\begin{array}{l}-.293^{* * *} \\
(.031)\end{array}$ \\
\hline Protestant & $\begin{array}{l}-.128^{* *} \\
(.042)\end{array}$ & $\begin{array}{l}-.055^{* * *} \\
(.021)\end{array}$ & $\begin{array}{l}-.010 \\
(.040)\end{array}$ & $\begin{array}{l}-.242^{* *} \\
(.034)\end{array}$ \\
\hline Buddhist & $\begin{array}{l}-.118 \\
(.079)\end{array}$ & $\begin{array}{l}.107^{* *} \\
(.049)\end{array}$ & $\begin{array}{l}-.072 \\
(.090)\end{array}$ & $\begin{array}{l}-.245^{* * *} \\
(.069)\end{array}$ \\
\hline Muslim & $\begin{array}{l}-.790^{* * *} \\
(.208)\end{array}$ & $\begin{array}{l}-.656^{* * *} \\
(.111)\end{array}$ & $\begin{array}{l}.103 \\
(.222)\end{array}$ & $\begin{array}{l}-.991^{* * *} \\
(.204)\end{array}$ \\
\hline Jews & $\begin{array}{l}.717^{* *} \\
(.286)\end{array}$ & $\begin{array}{l}-.037 \\
(.129)\end{array}$ & $\begin{array}{l}.181 \\
(.215)\end{array}$ & $\begin{array}{l}-.176 \\
(.133)\end{array}$ \\
\hline Other_religion & $\begin{array}{l}-.200^{* * *} \\
(.064)\end{array}$ & $\begin{array}{l}-.242^{* * *} \\
(.036)\end{array}$ & $\begin{array}{l}-.111^{*} \\
(.063)\end{array}$ & $\begin{array}{l}-.348^{* * *} \\
(.050)\end{array}$ \\
\hline Fixed effects & $\mathrm{Yes}^{* * *}$ & $\mathrm{Yes}^{* * *}$ & $\mathrm{Yes}^{* * *}$ & $\mathrm{Yes}^{* * *}$ \\
\hline Adj- $R^{2}$ & .0934 & 26.0610 & .078 & .118 \\
\hline Observations & 13244 & 28544 & 13266 & 19942 \\
\hline
\end{tabular}


this line of inquiry on two grounds in order to uncover the two key parameters of the extended family model: that is the preference for family activities and the strength of family ties. First, we directly look at individual attitudes towards the extended family rather than family arrangement outcomes. Second we provide new evidence on the extent to which family members share household activities between each other.

Let us first focus on attitudes towards the extended family. We start by looking at potential international differences in the perceptions of older people. The $W V S$ first provides some evidence regarding their role on the labor market by asking the following question: "When jobs are scarce, older people should be forced to retire from work early". Figure 13 reports the mean-reply against the country fixed effects which still capture national values. The sample is made up of people between 18 years old and 64 years old and is taken from the two waves 1990-93 and 199597. On average, Mediterranean countries and to a lesser extent Continental European countries are much more prone to support this statement than Nordic and Anglo-Saxon countries. But remarkably enough, this ordering is less clear-cut than before. In particular, Finland is much closer to Mediterranean countries than its Nordic counterparts in this realm. By contrast, Japan has the same stand on this issue as Nordic countries or the United States. This point is all the more remarkable that the Finnish employment rate of older workers is precisely close to the Mediterranean one while that of Japan is one of the highest among OECD countries with Sweden and the US. The Probit estimates of the other individual characteristics are reported in Table 2- Col.3. The probability to agree with early retirement is positively correlated with the fact to be a man, to have a partner or to have a low level of education.

Figure 13 also reports the family relations between prime age and older individuals captured by the following question: "Adult children have a duty to look after their elderly parents". The answer are scaled between "Agree, Disagree". Once again, there is a distinct cluster of Mediterranean countries (Italy, Spain) alongside with France which back such support within the family. In contrast, Nordic countries and Anglo-Saxon countries (with the exception of the US) seem much less concerned by such generational links.

Regarding attitudes towards young people, the most relevant available question for our issue is related to their independence and is provided by the WVS question: "Here is a list of qualities that children can be encouraged to learn at home. Which if any do you consider to be really important: Independence?". The answers are scaled between "Important, Not important". Following our previous strategy, Figure 13 reports the mean-reply on the x-axis against the proxy for family attitudes yielded by country fixed effects on the y-axis. The sample is still made up of the working age population on the two waves 1990-93 and 1995-97. On average, child independence appears to be a top quality for 75.1 percent of people in Nordic countries. 

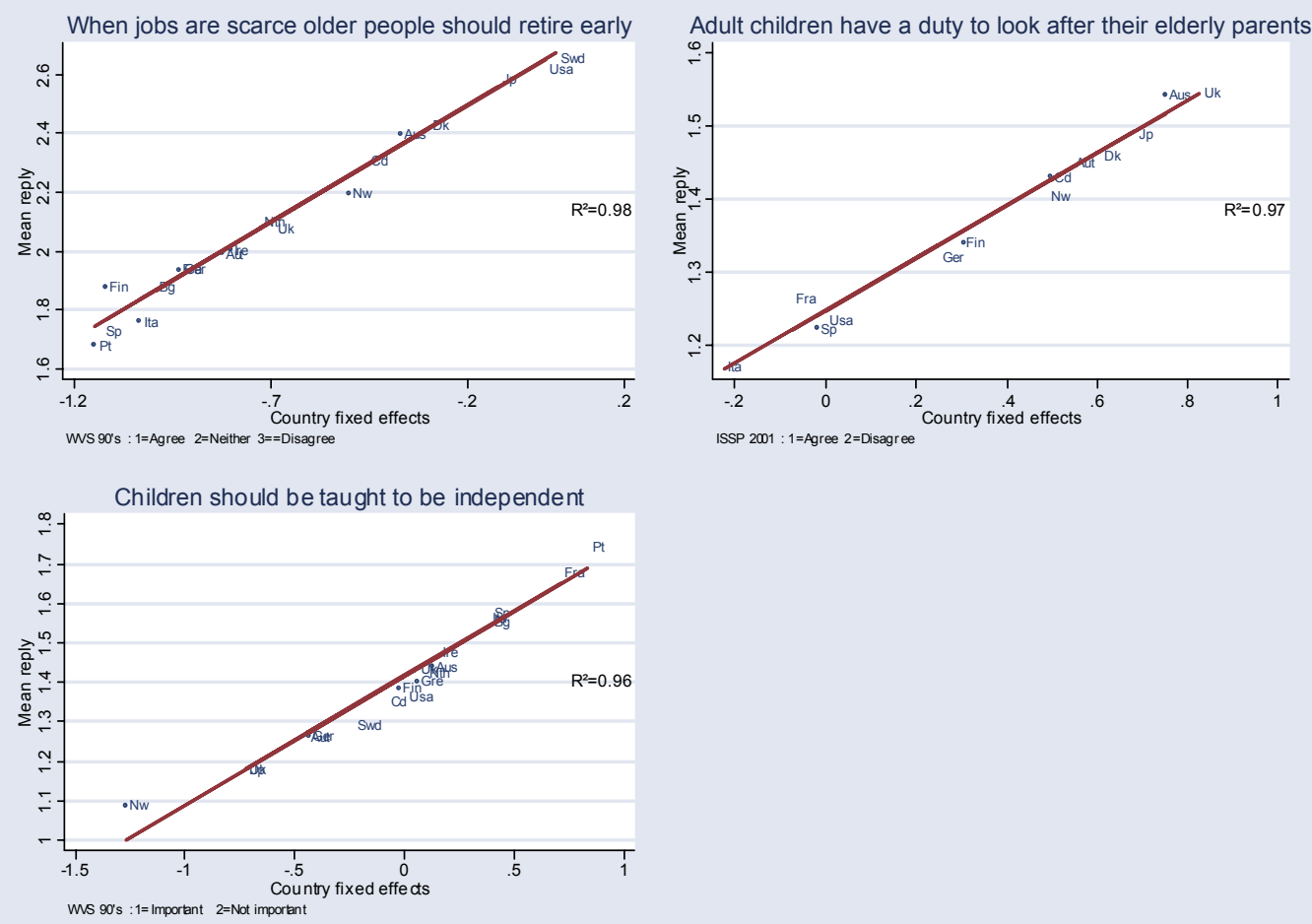

Figure 13: Family conception about older and young people in OECD countries.

This figure is twice as high as that of Mediterranean countries in which this quality is stressed by only 38.2 percent of the population. This opposition pattern also holds between Anglo-Saxon and Continental European countries. While 62 percent of American put the emphasis on child's independence, they are no more than 29 percent in France to follow this stand. This heterogeneity is largely shaped by national specificities. Even by controlling for standard characteristics and cultural features such as religious affiliation, the correlation between the mean-reply and the country fixed effects remains very high, the coefficient of determination being equal to 0.96 The effects of the other individual characteristics are reported in Table 2- Col.4. Promotion of child independence is negatively correlated with the fact to be a man, to belong to the right wing and to be either Catholic or Muslim.

Let us now turn to the relationships within the extended family. We address this issue by using a specific ISSP wave on social networks run in 2001. Due to the lack of data, we focus on four main countries representative of the main OECD clusters, namely Denmark, Germany, Spain and the United States. We first provide evidence that countries strongly differ in the strength of the contacts between the different family members. Figure 14-bottom left shows the 
share of children between 15 and 24 years old reporting to have at least daily physical contacts with their mother and conversely the share of elderly people having at least daily contacts with their adult daughter. Daily contacts include living in the same home. It turns out that contacts across generations are two times as high in Spain - and to a lesser extent in Germany - as in Denmark and the United Sates. But countries also highly differ regarding the way the different family generations share home activities. Figure 14-bottom right provides evidence on such discrepancies by reporting the mean reply for the question: "Suppose you had to stay in bed for a few days and needed help around the house, with shopping and so on. Who would you turn to first for help?". The answers involve relatives (husband, mother, father, daughter, son), social relations (from workplace, neighbors, friends) and private services. An overwhelming majority of young people would turn first to their mother in Spain and in Germany while they are no more than one third to share this reaction in the United States. If the differences are less sizeable regarding the answers given by older people, the same cross-country opposition pattern holds. These pictures suggest much stronger links between prime-age women and the other members of the family in Continental and Mediterranean European countries. Accordingly, one should expect much stronger interactions between female labor supply and that of the other demographic groups in these latter countries.

\subsubsection{Cultural foundations of family attitudes}

The observation of cross-country heterogeneity in family attitudes and family relations does not necessarily mean that individuals living in the same country share a common culture - i.e. common preferences for family ties or common skills in household production. Living in a specific country can influence one's own family perception and family relations through the channel of the relative economic returns of family and market activities. For instance, it is well known that child-care subsidies, paid maternity and parental leaves are more favorable to female waged work in Nordic countries than in Mediterranean countries (Jaumotte, 2003). This situation may lead individuals living in Mediterranean countries to declare more frequently that "preschool child suffers if the mother works". But it might be the case that individuals living in Mediterranean countries also share a common culture which makes them more prone to traditional family attitudes. In this case family policies would be the outcome rather than the cause of the family attitudes.

In order to investigate this issue, we look at the reactions of people who come from different national origins but face the same economic environment because they live in the same country. To that end, we use information provided by the ISSP on the ethnic or cultural backgrounds of the respondents "From what country or part of the world did your ancestor come from? If 


\section{Family ties}

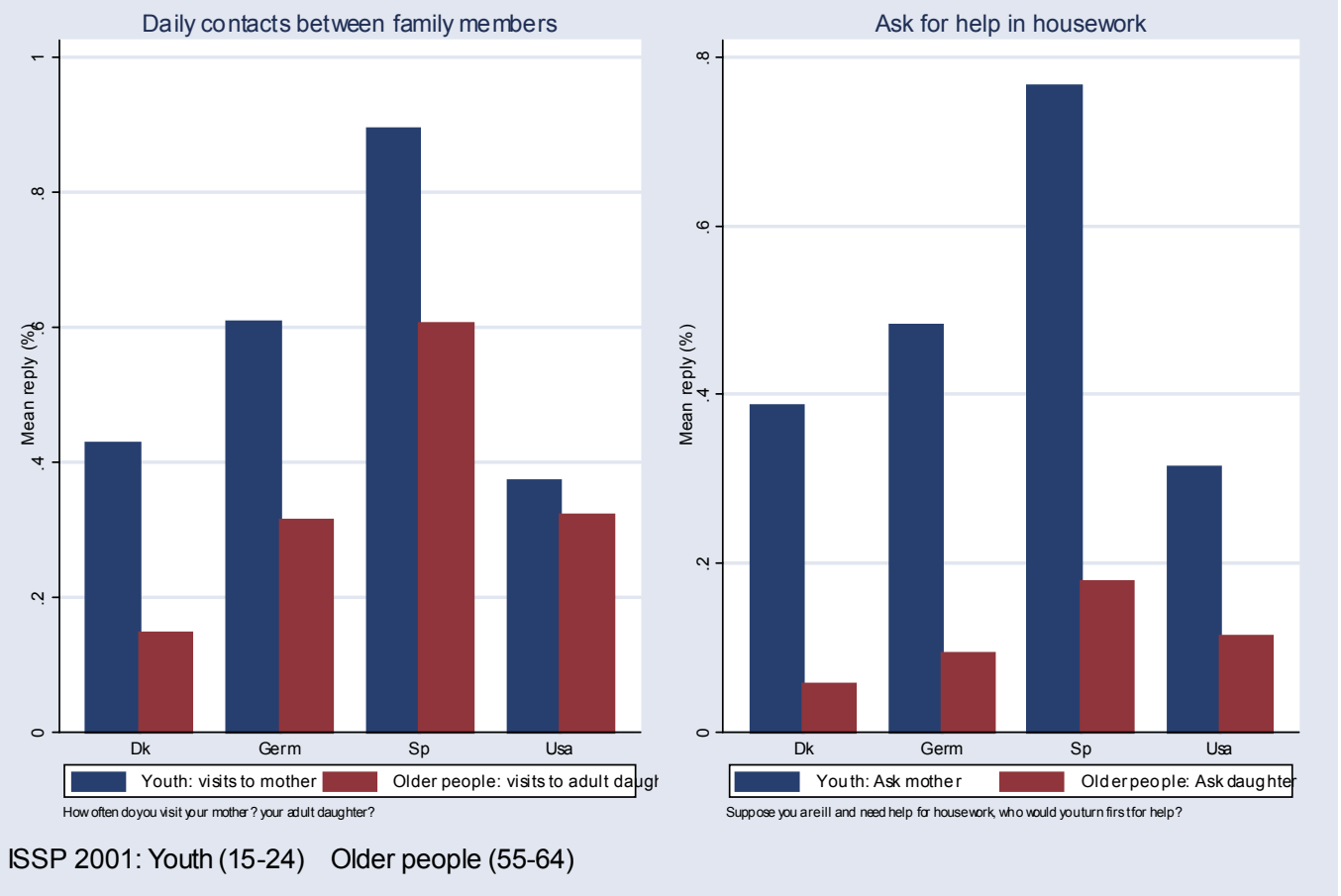

Figure 14: Family networks in OECD countries in 2001. 
there is more than one country, which one of these countries do you feel closer". ${ }^{20}$ Answers to this question are essentially provided for countries with a rich history of immigration and in particular for the United States on which our analysis is based. ${ }^{21}$ In order to use the maximum number of observations, we group the different countries of origins into the following clusters: European Continental countries (Austria, France, Germany, Netherlands), Mediterranean countries (Italy, Spain), and European Anglo countries (UK and Ireland). We also include people whose ancestor come from Latin American (overwhelmingly made up of Mexican) since they represent a substantial amount of the sample and can be used as a benchmark for comparing the other clusters (they display the most traditional perception of the family). We then assess to what extent the country of origins do matter by using dummies for each cluster. We also control for the main socio-demographic characteristics (age, sex, education, marital status, number of children, political orientation, religion) and the main economic variables captured by the employment status.

Table 3 shows the estimation results for the question "A preschool child suffers if the mother works". ${ }^{22}$ This question is available for the two specific surveys run by the ISSP on gender roles in 1994 and 2002. The sample is made up of the working age population. Table 3 - Col. 1 shows that individuals whose ancestors come from European Continental and Mediterranean countries or Latin America agree more frequently than those who originate from Nordic and English countries with the statement "A preschool child suffers if the mother works". Table 3 - Col. 2 reports the cross-country estimates run on the different countries belonging to the previous clusters. The comparison of Columns 1 and 2 indicates that the ordering of the country fixed effects associated with the country of the ancestors of people living in the US is the same as the ordering of country fixed effects associated with the country where people currently live. This suggests that individuals living in the US share some common family culture with people living in the countries of their ancestors. Accordingly, the perception of family is not only shaped by economic features that influence the relative economic returns of family and market activities. To some extent, the cross-country heterogeneity in family attitudes is shaped by cross country heterogeneity in family culture. From this perspective, it is worth analyzing the link between cross-country heterogeneity in family attitudes and cross-country heterogeneity in employment rates.

\footnotetext{
${ }^{20}$ Unfortunately we cannot use the $W V S$ questions on family attitudes in as much as this survey does not document the country of origins of the ancestors.

${ }^{21}$ The ISSP also provides some information about the ancestors' countries of people living in Canada. The same opposition pattern emerges between people with French and Anglo-Saxon origins. Yet this comparison may be more biased with specific regional policies.

${ }^{22}$ The other questions on gender roles - such as "Family life suffers when women works" or "A man's job is to earn money: a women's job is to look after home and family" - yield quantitatively similar results.
} 


\subsection{Labor market outcomes of family attitudes}

This section shows that family attitudes are highly correlated with the employment rates of the different demographic groups in OECD countries over the period 1970-2003. We first stress that the cross-national heterogeneity in family attitudes identified previously is significantly correlated with the cross-country dispersion in the level of employment rates. We then show that family perception displays a steady correlation with the dynamics of employment rates of the different demographic groups. Moreover, in accordance with the model, we find that a common exogenous shock on the price of household durable goods is correlated with contrasted changes in the labor supply of the demographic groups depending on family attitudes. Actually, the drop in the price of durable household goods over the last decades is significantly correlated with the rise in female labor supply in all countries. But this drop only displays a significant correlation with the labor supply of young and older people in countries with strong extended family ties.

\subsubsection{Family attitudes and employment rate levels}

We start by gauging the correlation between family attitudes and the level of employment rates of the different demographic groups. This issue is part of an emerging literature dealing with the link between family perception and labor market participation (see Neumark and Postlewaite, 1998, Fernandez et al., 2004). But the current literature generally focuses on individual labor supplies within the same country. We extend the analysis by looking at the cross-country aggregate outcomes of such family attitudes. To the best of our knowledge, no attempt has been made so far to quantify the relation between employment rates and family values in crosscountry times series. This caveat is partly due to the lack of suitable data. Indeed, we need both cross-national and cross-temporal evidence on family attitudes to disentangle the role of family perception from other specific country effects. We try to fill this gap by using the three main waves of the World Value Survey (1981-1983, 1990-1992, 1999-2002). ${ }^{23}$

In line with the previous section, we capture national family attitudes by the remaining country-fixed effects in the ordered probit estimates of individual attitudes towards family. But we run these estimates on each specific wave, which yields us different time observations for the family perception. The key issue is to relate these family attitudes to the employment rates at stakes during the corresponding periods. To compare stationary levels, we regress the 5year average value of the employment rate in the early eighties (1981-1984), the early nineties

\footnotetext{
${ }^{23}$ The wave 1995-97 displays a high number of missing data and is less exploitable. Note that the questions are not reported for all countries at each wave. The estimates are based on unbalanced samples.
} 
Table 3: Cultural roots of family attitudes: Ordered probit estimates

\begin{tabular}{|c|c|c|}
\hline & Estimations on the US (1) & Cross-country estimations (2) \\
\hline & Country of origins & Country of residency \\
\hline Latin America & \multicolumn{2}{|c|}{ Reference } \\
\hline Mediterranean & $\begin{array}{l}.133 \\
(.140)\end{array}$ & $\begin{array}{l}.331^{\text {*** }} \\
(.042)\end{array}$ \\
\hline European Continental & $\begin{array}{l}.215^{*} \\
(.122)\end{array}$ & $\begin{array}{l}.478^{* * *} \\
(.039)\end{array}$ \\
\hline European Anglo & $\begin{array}{l}.291^{* * *} \\
(.110)\end{array}$ & $\begin{array}{l}.937^{\text {*** }} \\
(.039)\end{array}$ \\
\hline Nordic & $\begin{array}{l}.512^{* * *} \\
(.202)\end{array}$ & $\begin{array}{l}1.084^{* * *} \\
(.043)\end{array}$ \\
\hline Men & $\begin{array}{l}-.339^{* * *} \\
(.065)\end{array}$ & $\begin{array}{l}-.238^{* * *} \\
(.016)\end{array}$ \\
\hline A ge & -.021 & -.004 \\
\hline & $(.011)$ & $(.003)$ \\
\hline Age2 & $\begin{array}{l}.000 \\
(.000)\end{array}$ & $\begin{array}{l}-.000^{*} \\
(.000)\end{array}$ \\
\hline Education & .015 & $.029^{* * *}$ \\
\hline (in years) & $(.012)$ & $(.001)$ \\
\hline Number & .003 & -.009 \\
\hline of child & $(.027)$ & $(.006)$ \\
\hline Partner & $\begin{array}{l}-.066 \\
(.073)\end{array}$ & $\begin{array}{l}-.043^{* *} \\
(.019)\end{array}$ \\
\hline Employed & $\begin{array}{l}.186^{* *} \\
(.077)\end{array}$ & $\begin{array}{l}.178^{\text {*** }} \\
(.019)\end{array}$ \\
\hline Political orientation: Center & \multicolumn{2}{|c|}{ Reference } \\
\hline Left & $\begin{array}{l}.205^{* * *} \\
(.077)\end{array}$ & $\begin{array}{l}.190^{* * *} \\
(.019)\end{array}$ \\
\hline Right & $\begin{array}{l}-.128^{*} \\
(.076)\end{array}$ & $\begin{array}{l}-.034^{*} \\
(.020)\end{array}$ \\
\hline Religion: Protestant & \multicolumn{2}{|c|}{ Reference } \\
\hline Catholic & $\begin{array}{l}.038 \\
(.030)\end{array}$ & $\begin{array}{l}-.045^{*} \\
(.025)\end{array}$ \\
\hline Atheist & $\begin{array}{l}.030 \\
(.098)\end{array}$ & $\begin{array}{l}.084^{* * *} \\
(.026)\end{array}$ \\
\hline Other_religion & $\begin{array}{l}.095 \\
(.160)\end{array}$ & $\begin{array}{l}-.328^{* * *} \\
(.048)\end{array}$ \\
\hline Income_class: Center & \multicolumn{2}{|c|}{ Reference } \\
\hline Low & $\begin{array}{l}.103 \\
(.075)\end{array}$ & $\begin{array}{l}.022 \\
(.020)\end{array}$ \\
\hline High & $\begin{array}{l}.128 \\
(.083)\end{array}$ & $\begin{array}{l}.174^{* * *} \\
(.021)\end{array}$ \\
\hline Adj- $\mathrm{R}^{2}$ & .03933 & .0802 \\
\hline $\mathrm{Nb}$ of informations & 1185 & 18438 \\
\hline
\end{tabular}

A negative sign increases the likelihood that individuals agree with the statement $\quad * * *: 1 \%, * *: 5 \%, *: 10 \%$ 
(1990-1994) and the late nineties (1995-1999) on the country fixed effects obtained from the estimations of family attitudes (see Table 2) over the three corresponding waves.

Figure 15 provides a first hint on the raw correlations between national family attitudes and employment rates in the early nineties. It first reports a significant positive correlation between prime-age female employment rate and the preferences over gender division of labour proxied by the country fixed effects for the question "When jobs are scarce, men should have more rights to a job than women" (WVS). Three main groups appear. The Nordic countries are the most opposed to male job priority and display the highest female employment rates. Anglo-Saxon and European Continental countries seem to share both the same attitudes towards gender roles and the same average female employment rates. Interestingly enough, a Mediterranean country like Portugal has preferences towards gender roles much closer to Anglo-Saxon and Continental countries and displays accordingly a pretty high female employment rate. The last group is made up of countries with both low employment rates and a positive bias in favor of male job priority. Typical countries belonging to this group are Italy, Greece, Ireland, Spain or Belgium and Japan.

Figure 15 also reports a significant correlation between the employment rate of older people and national attitudes over their role on the labor market as proxied by the fixed effects for the question "When jobs are scarce, older people should be forced to retire from work early". The coefficient of determination amounts to 0.46. But interestingly enough, this correlation does not square into the traditional opposition of countries. In particular Japan, the United States and some Nordic countries like Sweden are strongly at odds with a forced retirement and do have approximately the same employment rate of older people. By contrast, Finland, which is as favorable as Continental and Mediterranean countries to early retirement, displays the same employment rate pattern as these countries. Eventually, Figure 15 shows that the same significant correlation holds between youth employment rate and national family values over their independence proxied by the country fixed effects for the question: "Here is a list of qualities that children can be encouraged to learn at home. Which if any do you consider to be really important: Independence?". The same opposition pattern emerges between Mediterranean and European Continental countries characterized by both low youth employment rate and low concern for youth independence and at the other extreme Anglo-Saxon and Nordic countries which display the exact inverse picture.

This basic picture suggests a strong cross-country correlation between national perception of the role of each family members and their corresponding employment rates. Yet there may be alternative reasons for the above positive partial correlation such as labor market institutions 

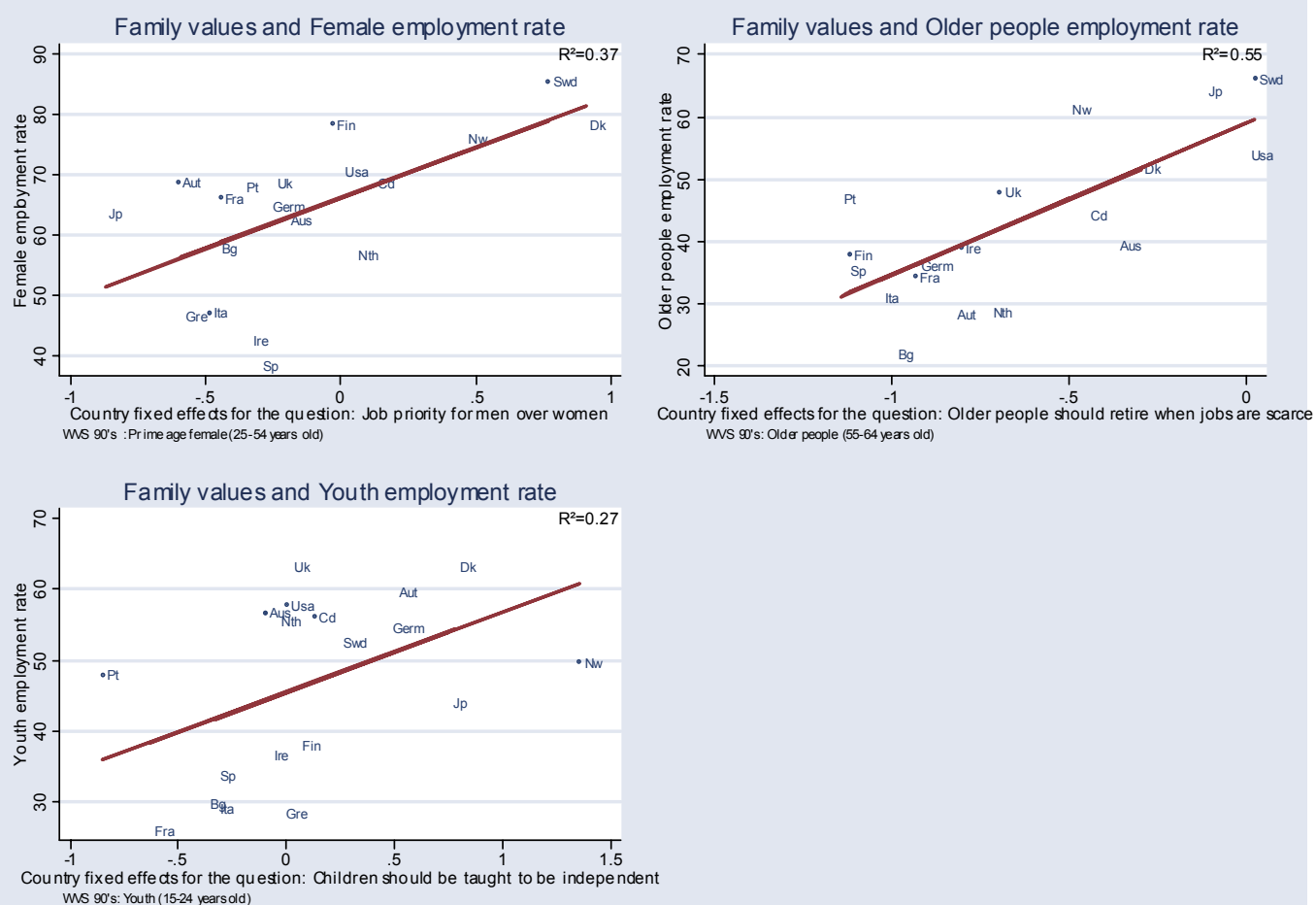

Figure 15: Correlation between national family attitudes and employment rates in OECD countries 
or family policies.

In what follows, we attempt at quantifying the specific contribution of family attitudes by taking account of the main variables used in the current labor market literature. We first control for the most relevant time-varying institutions accounted for by Nickell et al. (2001) and Bertola et al. (2002). Therefore, we include trade-union density, employment protection, tradeunion coordination and the level of unemployment benefit in the employment rate estimations of all demographic groups. Regarding female employment rate, we follow Jaumotte (2003) by including family policies - proxied by the share of public spending in child care - and sociodemographic variables captured by the Barro-Lee index of the number of years of education of women aged between 25 and 55 years old and the share of child per women. In order to understand youth employment, we also need to take into account of the number of years of education and subsidized education. Due to the availability of data, we focus on the level of education by using the Barro-Lee index on the average years of school of people aged between 15 and 25 years old. Eventually, the employment rate of older workers is likely to be affected by fiscal incentives to retire and the official age of retirement. We control for these characteristics by using Blondal and Scarpetta (1997) data on these two features. ${ }^{24}$

Obviously, the employment rates of the different demographic groups are potentially influenced by a number of other country specific variables. We control as far as we can for these specific features by including country fixed effects. Potential aggregate macroeconomic shocks are accounted for by including time period dummies. The prime age male unemployment rate is also included as a proxy for national labor market conditions.

Both the previous indicators and the employment rates by demographic groups are taken as 5 -year average. The sub-periods correspond to that of the national family attitudes indicators: the early eighties (1980-84), the early nineties (1990-94) and the late nineties (1995-99).

The GLS estimates are reported in Table 4. Each demographic employment rate is regressed on the corresponding family perception indicator, that is national attitudes towards i) gender roles in the case of prime-age female employment rate (25-54), ii) child independence for youth employment rate (16-24), and iii) early retirement for the employment rate of older people (55$64)$. Recall that the family indicator is made up of the coefficients associated with the countryfixed effects in the previous estimates of family attitudes. For each question, the country of reference is chosen as the one displaying the highest average answer in favor of male job priority

\footnotetext{
${ }^{24}$ We only report the estimations for the official age of retirement for which we have enough information for the period 1980-2000. Tax incentives are proxied by the expected increase in old-age pensions for a 55 year-old male by working for 10 years more. This indicator yields consistent results by increasing the participation of older worker but only cover two periods 1967 and 1995 .
} 
over women (Japan), early retirement of older individuals (Portugal), and low independence for children (France). Thus a positive coefficient associated with the national family indicator indicates a relative increase compared to the most "traditionalist" country in the probability to oppose job priority for men, to oppose early retirement for older workers, and to promote child independence.

Table 4 shows that for all demographic groups the corresponding national family indicator has a statistically highly significant impact on employment rates. Col. 2 and Col. 3 report that the fact to be at odds with job priority for men or to oppose early retirement for older people is significantly positively correlated with the employment rates of women and older individuals respectively. Besides, Col. 4 in Table 4 shows that national family attitudes relatively more favorable to child independence are positively correlated with youth employment rate. Strikingly enough, these national family indicators display a higher statistical power of explanation than most of the standard labor market institutions used in the current literature.

It is also instructive to try to quantify the economic meaning of the coefficients at stakes. Actually the previous coefficients are hardly interpretable by themselves since the family indicators consist of country fixed effects associated with answers coded in multiple values. To cope with this flaw, we have recoded the answers to the previous questions into agree-disagree (1-0) and run probit estimates with marginal effects. In this case, the national family perception indicators capture in each country the relative change in the probability of agreement with the related family statements compared to the most "traditionalist" country. We then estimate the impact of these new indicators on the employment rate of each demographic group by taking into account the previous labor market and family policies. It turns out that a relative decrease in national family preferences in favor of job priority for men or early retirement for older individuals is associated with an increase in female employment rate of 13 percent and a rise by 4.3 percent in the employment rate of older people respectively. Conversely, an increase in national family attitudes in favour of child independence relatively to the country which is the most opposed to this statement would be associated with an increase of 29.5 percent in youth employment rate. As a conclusion national family attitudes display a statistically significant and economically sizeable correlations with the employment rates of the different demographic groups in OECD countries.

\subsubsection{Family attitudes and the dynamics of employment rates}

This section shows that national family attitudes are also highly correlated with the dynamic evolution of employment rates. We examine to what extent the decline in the price of household 
Table 4: Family attitudes and employment rate levels: GLS estimates

\begin{tabular}{|c|c|c|c|}
\hline & $\begin{array}{l}\text { Employment rate } \\
\text { Women } \\
\text { (1) }\end{array}$ & $\begin{array}{l}\text { Employment rate } \\
\text { Older people } \\
\text { (2) }\end{array}$ & $\begin{array}{l}\text { Employment rate } \\
\text { Young people } \\
(3)\end{array}$ \\
\hline Family attitudes & $\begin{array}{l}.077^{* * *} \\
(.002)\end{array}$ & $\begin{array}{l}.019^{* *} \\
(.008)\end{array}$ & $\begin{array}{l}.076^{* * *} \\
(.015)\end{array}$ \\
\hline Employment protection & $\begin{array}{l}.005 \\
(.005)\end{array}$ & $\begin{array}{l}-.048^{* *} \\
(.022)\end{array}$ & $\begin{array}{l}.036 \\
(.029)\end{array}$ \\
\hline Union coordination & $\begin{array}{l}.034 \\
(.021)\end{array}$ & $\begin{array}{l}-.003 \\
(.014)\end{array}$ & $\begin{array}{l}-.019 \\
(.013)\end{array}$ \\
\hline Union density & $\begin{array}{l}-.065 \\
(.123)\end{array}$ & $\begin{array}{l}-.228^{* * *} \\
(.039)\end{array}$ & $\begin{array}{l}.476^{* * *} \\
(.078)\end{array}$ \\
\hline Unemployment benefit & $\begin{array}{l}-.024 \\
(.071)\end{array}$ & $\begin{array}{l}-.125^{* * *} \\
(.034)\end{array}$ & $\begin{array}{l}.317^{* * * *} \\
(.045)\end{array}$ \\
\hline $\begin{array}{l}\text { Unemployment rate } \\
\text { Prime-age men }\end{array}$ & $\begin{array}{l}-.922^{* * *} \\
(.242)\end{array}$ & $\begin{array}{l}-.040 \\
(.112)\end{array}$ & $\begin{array}{l}-.240^{* * *} \\
(.018)\end{array}$ \\
\hline Children per women & $\begin{array}{l}-.084 \\
(.095)\end{array}$ & & \\
\hline Education & $\begin{array}{l}.032^{* *} \\
(.013)\end{array}$ & $\begin{array}{l}-.005 \\
(.005)\end{array}$ & $\begin{array}{l}-.006 \\
(.006)\end{array}$ \\
\hline Family policy & $\begin{array}{l}.006^{* * *} \\
(.001)\end{array}$ & & \\
\hline Off. age retirement & & $\begin{array}{l}.007^{* * *} \\
(.001)\end{array}$ & \\
\hline $\begin{array}{l}\text { Period effects } \\
\text { Fixed effects }\end{array}$ & & $\begin{array}{l}\text { Yes }^{* * *} \\
\mathrm{Yes}^{* * *}\end{array}$ & \\
\hline $\mathrm{Nb}$ of informations & 49 & 53 & 53 \\
\hline $\begin{array}{l}\text { (1) Country Fixed effe } \\
\text { (2) Country fixed effect } \\
\text { (3) Country fixed effects }\end{array}$ & $\begin{array}{l}\text { Ttes : GLS estima } \\
\text { National fami } \\
\text { in "When jobs ar } \\
\text { "When jobs are } \\
\text { "Children should }\end{array}$ & $\begin{array}{l}\text { th heteroskedastic } \\
\text { itudes proxied by: } \\
\text { ce,men should have } \\
\text { e,older people shou } \\
\text { ught to become in }\end{array}$ & $\begin{array}{l}\text { ority over women" } \\
\text { earlier" } \\
\text { nt" }\end{array}$ \\
\hline
\end{tabular}


durable goods is correlated not only to the labor supply of women but also to the labor supply of the extended family members. The theoretical model predicts that the rise in home production triggered by the decline in the price of household durable goods should create incentives for younger and older individuals to devote more time to family activities and to decrease their labor supply. But this effect is expected to be significant in countries which have been previously found to have strong national attachment to family relations only.

To test this correlation pattern, we use cross-national evidence on the evolution of household durable goods prices over the last decades. This dataset - constructed by Eurostat - provides yearly information on the price index of home appliances for a sample of OECD countries since $1975 .{ }^{25}$ The index only includes household appliances intended to save labor in household cleaning and maintenance such as vacuums, washing machines, clothes dryers, dishwasher, microovens. But it excludes furniture and audiovisual appliances. ${ }^{26}$ The relative price of home appliances is computed as the ratio of the home appliance price index to consumer price index by taking 1985 as the reference year. The country with enough reliable data are: Denmark, France, Germany, Italy, Spain, United Kingdom and the United States. In all countries, the relative price of home appliances has dramatically fallen, with an average yearly drop of 1 percent.

Table 5 reports the GLS estimates of the correlation pattern between household good durable prices and the employment rate of young and older people. To evaluate the differential impact of the price of household durable goods depending on family relations, we group the countries into the main four clusters identified in the previous analysis of national family attitudes: Anglo-Saxon countries, European continental countries (France and Germany), Mediterranean countries (Italy and Spain) and Scandinavian countries (Denmark). To identify the specific role of household durable good price on the employment rate of young and older people, we also include the same time-varying labor market institutions (Nickell et al, 2001) as the previous estimations. Yet, we do not include the average level of education and the tax incentives for retirement for which we do not have yearly information. We try to partly overcome this lack of data by including both country fixed effects and time period dummies. The regressions are based on the period 1975-1995.

Column 1 in Table 5 first shows a high discrepancy in the correlation pattern between youth employment rates and durable goods prices. There is a robust positive correlation in Mediterranean and Continental countries, an increase in the home appliance price being associated with

\footnotetext{
${ }^{25}$ This database has been used by Cavalcanti and Tavares (2004) for assessing the role of durable price on female labor supply. We extend this analysis to other demographic groups and stress the key interactions between prices and preferences.

${ }^{26}$ Cavalcanti and Tavares (2004) used this dataset to show the significant impact of the price of household durable goods on female labor supply. We thus directly focus on the labor supply of extended family members and their contrasted evolution by groups of countries.
} 
a 0.37 percent decrease in youth employment in these groups of countries. By contrast, the correlation between these two variables becomes negative and is no longer statistically significant in Anglo-Saxon and Scandinavian countries. As to the effects of traditional labor institutions, employment protection and unemployment benefits have a significant negative impact. Column 2 in Table 5 provides a mirror image regarding the correlation between the employment rate of older worker and the price of household durable goods. The most noticeable result is the sizeable positive correlation between the employment rate of this demographic group and the relative appliance price index in Mediterranean and Continental countries. The correlation is statistically significant at the $5 \%$ level. By contrast, the correlation turns out to be negative in Anglo-Saxon and in Denmark and is no longer statistically significant. This finding suggests that the same technological shock to home production may have led to significant cross-national differences in the employment path of younger and older individuals depending on national family attitudes.

\section{Conclusion}

Is the low European employment rate rooted in specific European family culture? Although this paper is far from providing a definitive stand on this issue, we show converging evidence in favor of a positive answer to this question. First, the European employment gap is overwhelmingly concentrated on demographic groups for which the European dominant family perception is precisely unfavorable to their labor market participation. Second, the evolution of the employment rates of the different demographic groups over the last decades has been highly correlated in countries displaying strong preferences for family relations, the upward trend in female labor supply having led to a dramatic fall in youth and senior employment rates in European countries only. This evolution pattern suggests strong labor supply composition effects within the family in countries which are found to be more attached to family ties. Eventually, we have shown that family attitudes are influenced by cultural factors in as much as people sharing the same backgrounds from their ancestors but facing different economic environment tend to react identically on family issues.

Naturally, the identification of cultural factors remains a complex issue since culture may deeply interact with institutions and evovle with the economic environement. ${ }^{27}$ As preferences are likely to be influenced by labor market experience, culture cannot be considered as an exogenous variable out of reach from labor market institutions. Conversely, institutions also depend on family preferences ${ }^{28}$ as far as they are shaped by individuals.

\footnotetext{
${ }^{27}$ See Bisin and Verdier (2001) for an analysis of the dynamics of preference and cultural evolution.

${ }^{28}$ See Algan and Cahuc (2004) for a political economy analysis of job protection based on male breadwinner values.
} 
Table 5: Household durable good prices and employment rates: GLS estimates

\begin{tabular}{|c|c|c|}
\hline Variables & $\begin{array}{l}\text { Employment rate } \\
\text { Young people } \\
\text { (1) }\end{array}$ & $\begin{array}{l}\text { Employment rate } \\
\text { Older people } \\
\text { (2) }\end{array}$ \\
\hline \multicolumn{3}{|l|}{ Household durable goods prices } \\
\hline Anglo countries & $\begin{array}{l}-.114 \\
(.073)\end{array}$ & $\begin{array}{l}-.187 \\
(.092)\end{array}$ \\
\hline Mediterranean countries & $\begin{array}{l}.377^{* * *} \\
(.127)\end{array}$ & $\begin{array}{l}.242^{* *} \\
(.102)\end{array}$ \\
\hline Continental countries & $\begin{array}{l}.368^{* * *} \\
.151)\end{array}$ & $\begin{array}{l}.029^{* *} \\
(.001)\end{array}$ \\
\hline Scandinavian countries & $\begin{array}{l}-.156 \\
(.335)\end{array}$ & $\begin{array}{l}-.273 \\
(.309)\end{array}$ \\
\hline Employment protection & $\begin{array}{l}-.204^{* * *} \\
(.030)\end{array}$ & $\begin{array}{l}-.042 \\
(.004)\end{array}$ \\
\hline Unemployment benefit & $\begin{array}{l}.120^{* * *} \\
.037)\end{array}$ & $\begin{array}{l}-.042 \\
(.044)\end{array}$ \\
\hline Union coordination & $\begin{array}{l}-.018 \\
(.015)\end{array}$ & $\begin{array}{l}.002 \\
(.024)\end{array}$ \\
\hline Union density & $\begin{array}{l}-.031 \\
(.062)\end{array}$ & $\begin{array}{l}-.162 \\
(.106)\end{array}$ \\
\hline Unemployment rate & $-.894^{* * *}$ & -.001 \\
\hline Prime-age men & $(.104)$ & $(.001)$ \\
\hline Constant & $\begin{array}{l}.311^{*} \\
(.179)\end{array}$ & $\begin{array}{l}.973^{* *} \\
(.308)\end{array}$ \\
\hline Fixed effects & \multicolumn{2}{|c|}{$\mathrm{Yes}^{* * *}$} \\
\hline Time effects & \multicolumn{2}{|c|}{$\mathrm{Yes}^{* * *}$} \\
\hline Nb observ. & \multicolumn{2}{|c|}{127} \\
\hline
\end{tabular}

GLS estimates with heteroskedastic standard errors.

*** : $1 \%, * *: 5 \%, *: 10 \%$ 


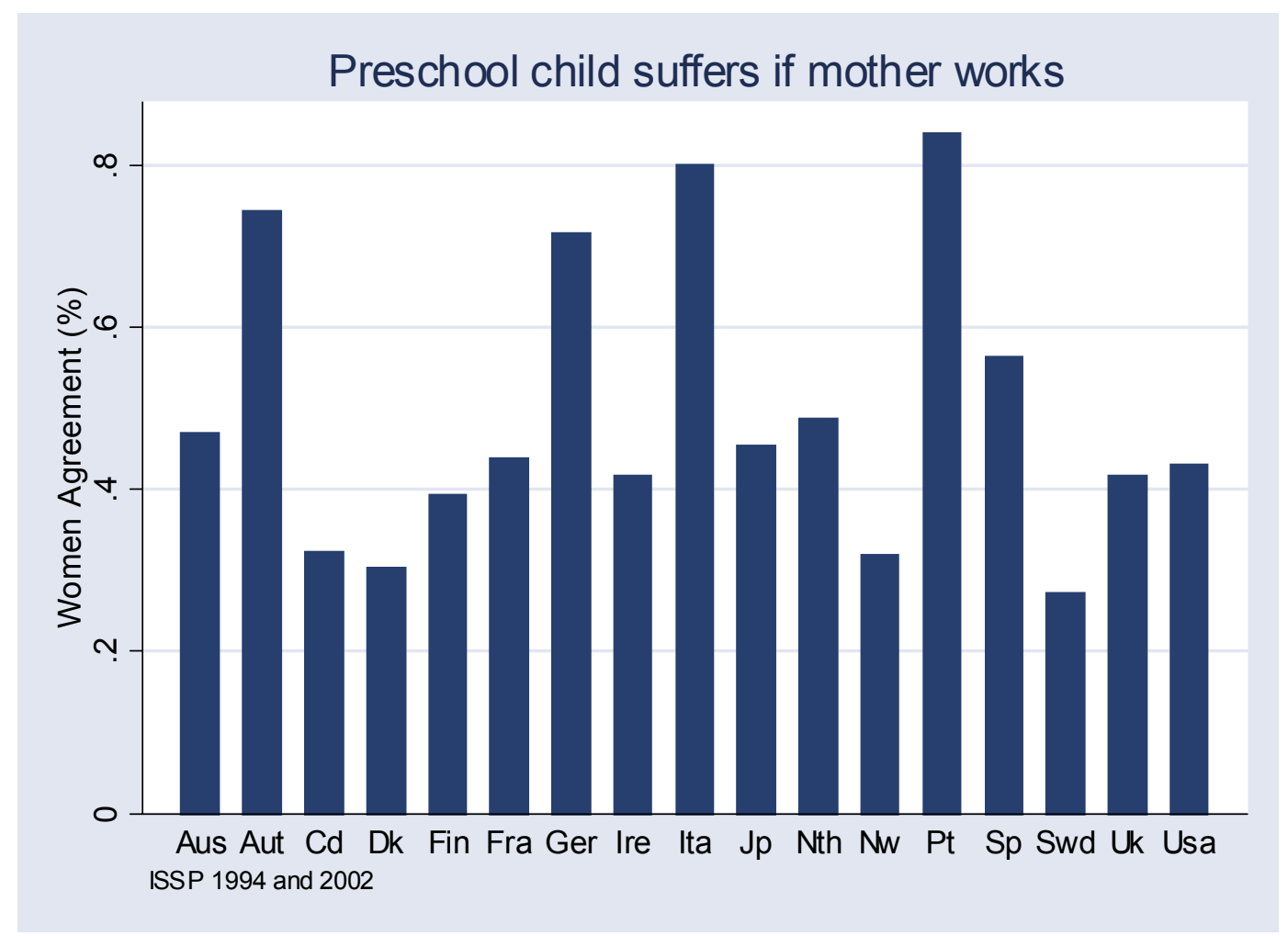

Figure 16: Share of women who agree or strongly agree with the statement "A prescholl child suffers if mother works"

Yet we argue that deepening the cultural roots of low European employment rates remains a top agenda issue for both positive and normative analysis of labor market outcomes. For instance, let us consider the current European policy recommendations to promote the employment rates of mothers in European Continental and Mediterranean countries. Actually, Figure 16 shows that an overwhelming majority of women in these countries do agree (or strongly agree) with the statement "A preschool child suffers if the mother works". And it has been shown in the core paper that this response is likely to be linked to cultural perception of motherhood rather independently of policy incentives. To that regard, the implementation of the European recommendations of the Lisbon strategy might well not be welfare improving. 


\section{References}

[1] Algan, Y., and Cahuc, P., 2004, Job protection: the Macho hypothesis, IZA Working Paper $\mathrm{n}^{\circ} 1192$.

[2] Antecol, H., 2000, An Examination of Cross-Country Differences in the Gender Gap in Labor Force Participation Rates, Labour Economics 7, pp. 409-426.

[3] Becker, S. O., Bentolila, S., Fernandes, A., and Ichino, A., 2004, Job insecurity and children's emancipation. Mimeo, CEMFI.

[4] Bentolila, S. and Ichino, A., 2000, Unemployment and Consumption: Are Job Losses Less Painful near the Mediterranean?, CEPR Working Paper, n $^{\circ} 2539$.

[5] Bertola, G., Blau, F.D, and Kahn, L., 2002, Labor Market Institutions and Demographic Employment Patterns, CEPR Working Paper, n 3348.

[6] Bergstrom, T.C., 1997, A Survey of the Theory of the Family, Handbook of Population and Family Economics, Rosenzweig, M.R. and Stark, O. (eds), chap 2, pp. 22-79.

[7] Bisin, A., et Verdier, T., 2001, The Economics of Cultural Transmission and the Dynamics of Preferences, Journal of Economic Theory, 97, 298-319.

[8] Blanchard, O., 2004, The Economic Future of Europe, Journal of Economic Perspective, 18.

[9] Blau, F., 1992, The fertility of immigrant women: evidence from high fertility source countries. In: Borjas, G.J., Freeman, R. Eds. , Immigration and the workforce: economic consequences for the United States and source areas. The University of Chicago Press, Chicago, pp. 93-133.

[10] Blondal, S. and Scarpetta, S., 1997, Early retirement in OECD countries: The role of social security systems, OECD Economic Studies nº29.

[11] Cavalcanti, T. and Tavares, J., 2004, Women Prefer Larger Governments: Female Labor Supply and Public Spending, Lisbon University Working Paper.

[12] Diaz, A., and Guillo, D., 2004, Family Ties and Labor Supply, Working Paper, Department of Economics, Universidad Carlos III.

[13] Ermisch, J., 1999, Price, parents, and young people's household formation. Journal of Urban Economics, 45, pp. 47-71. 
[14] Fernandez, R., Fogli, A., and Olivetti, C., 2004, Mother and Sons: Preference Formation and Female Labor Force Dynamics, Quarterly Journal of Economics, 119, pp. 1249-1299.

[15] Fernandez, R. and Fogli, A., 2005, Culture: An Empirical Investigation of Beliefs, Work, and Fertility, Federal Reserve Banck of Minneapolis, Research Department Staff Report 361.

[16] Fogli, A., 2000, Endogenous Market Rigidities and Family ties, New York University working paper.

[17] Freeman, R.B., and Schettkat, R., 2005, Marketization of household production and the EU-US gap in work, Economic Policy, 41, pp. 5-50.

[18] Galor, O. and Weil, D., 1996, The Gender Gap, Fertility and Growth, American Economic Review, 86, pp. 374-387.

[19] Gianelli, G. C. and Monfardini, C., 2003. Joint decisions of household membership and human capital accumulation of youths. the role of expected earnings and local markets. Journal of Population Economics 16, pp. 265-285.

[20] Giuliano, P., 2004, On the Determinants of Living Arrangements in Western Europe: Does Cultural Origin Matter?, mimeo, U.C. Berkeley.

[21] Goldin, C., 1990, Understanding the Gender Gap: An Economic History of American Women, New York: Oxford University Press.

[22] Grant, J.H and Hamermesh, D.S, 1982, Labor Market Competition Among Youths, White Women and Others, Review of Economics and Statistics, pp. 354-360.

[23] Greenwood, J., Seshadri, A. and Yorukoglu, M., 2005, Engine of Liberalization, Review of Economic Studies, 72, pp. 109-133.

[24] Guinnane, T., Moehling, C. and Grada, C., 2002, The Fertility of the Irish in America in 1910, mimeo, Yale University.

[25] Jaumotte, F., 2003, Female labour force participation: past trends and main determinants in OECD countries, OECD working paper (2003)30.

[26] Martınez-Granados, M. and Ruiz-Castillo, J., 2002, The decisions of Spanish youth: A cross section study. Journal of Population Economics, 15, pp. 305-330. 
[27] Neumark, D. and Postlewaite, A., 1998, Relative Income Concerns and the Rise in Married Women's Employment, Journal of Public Economics, pp. 157-183.

[28] Nickell, S., Nunziata, L., Ochel, W. and Quintini, G., 2001, The Beveridge curve, Unemployment and Wages in OECD from the 1960s to the 1990s, LSE working paper $\mathrm{n}^{\circ} 0502$.

[29] Pissarides, C., Garibaldi, P., Olivetti, C. and Wasmer, E., 2004, "Women in the labor force: How well is Europe doing?" in T. Boeri, D. del Boca and C. Pissarides (eds.), European Women at Work, Oxford University Press.

[30] Reimers, C.W., 1985. Cultural differences in labor force participation among married women. American Economic Review, Papers and Proceedings, 75, pp. 251-255.

[31] Rogerson, R., 2003, Structural Transformation and the Deterioration of European Labor Market Outcomes, Working paper, Arizona State University.

[32] Wasmer, E., 2001, The Causes of the Youth Employment Problem: A Labor Supply Side View, in The New Economics of Rising Inequalities, in Cohen, D., Piketty, T. and SaintPaul, G., eds. 